\title{
Changes in flavour, emotion, and electrophysiological measurements when consuming chocolate ice cream in different eating environments
}

\author{
Yun Xu ${ }^{\text {a }}$, Nazimah Hamid ${ }^{\text {a, }}$, Daniel Shepherd ${ }^{b}$, Kevin Kantono ${ }^{\text {a }}$, Charles Spence ${ }^{\mathrm{c}}$ \\ a Department of Food Science, Auckland University of Technology, Private Bag 92006, Auckland 1142, New Zealand \\ ${ }^{\mathrm{b}}$ Department of Psychology, Auckland University of Technology, Private Bag 92006, Auckland 1142, New Zealand \\ ${ }^{c}$ The Crossmodal Research Laboratory, Department of Experimental Psychology, Anna Watts Building, University of Oxford, Oxford OX2 6GG, UK
}

\section{ART ICLE INFO}

\section{Keywords:}

Chocolate ice cream

Eating environment

TDS

Electrophysiological measurements

Emotion

\begin{abstract}
A B S T R A C T
The eating context influences eating behaviour as well as the hedonic response to food. This study investigated temporal changes in the perceived flavour of chocolate ice cream when consumed in a laboratory, café, university study area, and a city bus stop, and further examined how emotion and electrophysiological measures were influenced by these environments. In this study, three measures were obtained from 160 participants. First, temporal changes in multisensory flavour perception after consuming chocolate ice cream in different environments were determined using the Temporal Dominance of Sensations (TDS) method. Second, participants' emotional responses were measured after consuming ice cream using a check-all-that-apply (CATA) list of emotions. Finally, standard electrophysiological measures of heart rate (HR), blood volume pulse (BVP), and skin conductance (SC) were also obtained. When ice cream was consumed in the café, it was associated with positive emotions and a sweet taste/flavour. When consumed in the university study area, it was correlated with both positive and negative emotions, and cocoa and milky flavours. Consumption at the city bus stop was correlated with the most negative emotions, and with roasted and bitter tastes/flavours. The laboratory environment was only correlated with the attributes of 'concentrating' and creamy flavour. SC was significantly increased in the university study area as compared to the laboratory, and HR was significantly decreased in the university study area environment as compared to the bus stop. The evidence from this study therefore indicates that the eating context constitutes an important factor to consider when carrying out sensory testing as participants' emotions, perceptions, and electrophysiological responses are influenced differently dependent upon the eating context.
\end{abstract}

\section{Introduction}

The sensory testing of food is often carried out in a laboratory setting in order to accurately analyse the sensory attributes of products (e.g., see Pound, Duizer, \& McDowell, 2000). However, in real life, people consume foods in a host of different eating environments, that are mostly typically far removed from that of the science laboratory. However, sensory testing in a controlled environment such as a sensory laboratory might not provide a good indication of food perception as consumption takes place under highly controlled conditions (Hersleth, Ueland, Allain, \& Næs, 2005; Kim, Lee, \& Kim, 2016; see Spence, 2017a, for a review). Most research has shown that consuming food in a central test location (Hersleth, Mevik, Næs, \& Guinard, 2003; Petit \& Sieffermann, 2007; Pound et al., 2000), in the home (Daillant-Spinnler

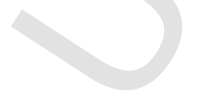

\footnotetext{
* Corresponding author.

Email address: nhamid@aut.ac.nz (N. Hamid)
}

\& Issanchou, 1995; Kozlowska et al., 2003; Pound et al., 2000; Zhang, 2017), and in immersive environments (Bangcuyo et al., 2015; Hathaway et al., 2017) result in significantly higher hedonic ratings than when a laboratory environment is used. These studies confirm that food consumption in everyday eating environments may well have more ecological validity than offered by laboratory testing (Kim et al., 2016; Pound et al., 2000). In view of all that has been mentioned so far, one may suppose that the flavour of food and drink may change when eating in different environments. That change might be in terms of either the sensory-discriminative and/or the hedonic response.

Studies on how eating environments influence food perception have mainly focused on acceptability (Bangcuyo et al., 2015; Bell, Meiselman, Pierson, \& Reeve, 1994; Jiang, Niimi, Ristic, \& Bastian, 2017; King, Weber, Meiselman, \& Lv, 2004), and eating behaviour (Stroebele \& De Castro, 2004). Very little published research has investigated temporal changes in flavour perception in different eating envi- 
ronments. To date, only Kantono et al. (2018) have investigated the effect of music on flavour dynamics under different environmental conditions (laboratory, immersive, and natural eating environment). The authors demonstrated that cocoaness, sweetness, and milkiness were cited more in the natural eating environment than in the laboratory setting, and bitterness and creaminess were least cited. In addition, it was found that music varying in valence evoked emotions, which influenced the temporal sensory attributes of chocolate gelati in the different eating environments. Flavour perception can be influenced by mood state (i.e., hedonic tone of pleasantness; Seo \& Hummel, 2010) and heightened emotional state (Woods et al., 2011; Wang \& Spence, 2018). Thus, understanding the relationship between consumer emotions and sensory food perception is important as it may potentially provide a better understanding of consumers' product experiences (Spinelli \& Monteleone, 2018).

A number of different sensory science approaches have been developed to assess the emotions associated with food. Most studies use questionnaires that comprise a forced yes/no variant of CATA questions (Cardello \& Jaeger, 2016). Valence and arousal are important descriptive features of all emotions that characterise the core level of affect (Barrett, 2016). Emotional valence illustrates the extent to which an emotion is positive or negative, while arousal indicates the strength of the associated emotional state (Russell, 2003). More objective physiological measures known to covary with emotional states (i.e., cardiovascular, respiratory, and skin conductance responses) can also be used. Electrophysiological measurements can covary with food-related emotions (Nijs, Franken, \& Muris, 2010). Subjective measures of emotions can be supplemented by measuring autonomic nervous system (ANS) activity that controls organ functions via parasympathetic (relaxation) and sympathetic (activation) branches, which can influence and reflect emotional responses (Kreibig, 2010). Wioleta (2013) reported that physiological signals like blood volume pulse (BVP), blood pressure (BP), skin conductance (SC), and heart rate (HR) can be informative when analysing participants' emotions. Kantono et al. (2019) postulated that an affective mechanism mediated the relationship between music valence and the perception of chocolate gelato. Their study successfully demonstrated the use of electrophysiology measures to augment subjective measurements of emotion in order to explain the temporal changes in perceptions of chocolate gelato while listening to music varying in valence. They reported that both of these measures were robust predictors of changes in flavour perception of gelato while listening to music. The authors explained that an affective (or 'emotion') mechanism mediated the relationship between music valence and the perception of gelato, and suggested that the use of electrophysiological measures could be used to augment subjective measurements of emotion.

A consumer's emotional state can be influenced by the environment in which consumption is taking place (Edwards \& Gustafsson, 2008), for instance, due to lighting, background music, spatial layout, and/or temperature (Heung \& Gu, 2012). According to the Mehrabian and Russell (1974) model (M-R), participants' emotional responses (i.e., arousal, dominance, and pleasure) can be influenced by environmental factors such as colour, odour, texture, sound, and temperature. Recent studies have demonstrated that restaurant atmospherics have a significant effect on the emotions of consumers in terms of positive emotions (Jang \& Namkung, 2009; Jang, Liu, \& Namkung, 2011; Jeong \& Jang, 2011; Prayag, Khoo-Lattimore, \& Sitruk, 2014), arousal (Hyun \& Kang, 2014; Ryu \& Jang, 2007) and pleasure (Kim \& Moon, 2009; see Spence, 2017a, for a review). Danner et al. (2016) further demonstrated that positive emotions were rated significantly higher in the restaurant environment after consuming wine compared to consuming in the home and laboratory environments. These researchers attributed the latter results to the social interactions that participants had in the restaurant. Additionally, Schouteten, De Steur, Sas, De Bourdeaudhuij, and
Gellynck (2017) reported that positive emotions were rated significantly higher at home when consuming yogurt as compared to when in the sensory laboratory. Dorado, Chaya, Tarrega, and Hort (2016) further showed that positive emotions were significantly increased, and negative emotions significantly decreased, when drinking beer in central locations with freely-elicited scenarios (i.e., talking with friends) as compared to the control environment. From these studies, it is evident that emotional experiences of consumers vary in different eating environments. It is hypothesised that these changes may, in turn, influence the multisensory perception of the flavour of ice cream.

Researchers have investigated how environmental factors influence electrophysiological processes. For example, noisy environments with public transport have been shown to increase BP (Belojevic, Jakovljevic, Stojanov, Paunovic, \& Ilic, 2008; Dratva et al., 2012; Kjellgren \& Buhrkall, 2010; Paunović, Belojević, \& Jakovljević, 2014), HR (Belojevic et al., 2008), and SC (Alvarsson, Wiens, \& Nilsson, 2010). Environments near shopping centres (Dubowitz et al., 2012) and pedestrian-friendly neighbourhoods (Dubowitz et al., 2012; Li, Harmer, Cardinal, \& Vongjaturapat, 2009), by contrast, lead to a significant decrease in BP instead. As electrophysiological measures typically correlate with an individual's emotional state, these studies indicate that environmental factors can induce negative and positive emotions alongside changes in physiological response. Speculatively, then, the types of environments in which the consumer finds themselves will likely also influence their perception of food.

It is evident, then, that studies have now convincingly demonstrated that different eating environments can affect consumers' hedonic, emotional, and electrophysiological responses. Hence, the specific objective of the present study is to determine how the temporal aspects of flavour perception, consumer emotion, and electrophysiological measurements are influenced by the laboratory and real eating environments when consuming chocolate ice cream. It was hypothesized that different eating environments would influence affective states that would, in turn, result in temporal changes in the multisensory perception of ice cream. The relationship between sensory, emotion, and ANS measures obtained after consuming ice cream in the different eating environments will then be further evaluated.

\section{Materials and methods}

\subsection{Experimental procedure}

The flow chart shown in Fig. 1 depicts the experimental design used in this research. Chocolate ice cream was consumed by participants in four different environments as shown in Fig. 2: (a) sensory testing laboratory, (b) café, (c) bus stop, and (d) university study area. In each environment, electrophysiological, sensory and emotional measures were obtained. First, electrophysiological measurements were obtained while the participants were seated comfortably in each environment for a 5-min baseline measurement when not consuming ice cream, and finally for 1-min while consuming ice cream. Second, the Temporal Dominance of Sensations (TDS) method was used to measure temporal changes in the flavour of chocolate ice cream over a $45 \mathrm{~s}$ period. At the end of TDS assessment, participants rated the affective attributes of the stimuli in terms of valence, arousal, and dominance. The participants also selected emotions elicited by each environment from a list of emotions provided. There were compulsory five minute breaks between electrophysiological, sensory, and emotion measurements.

\subsection{Ethics statement}

Ethical approval for this study was granted by the Auckland University of Technology Ethics Committee (AUTEC 17/202). The partici- 


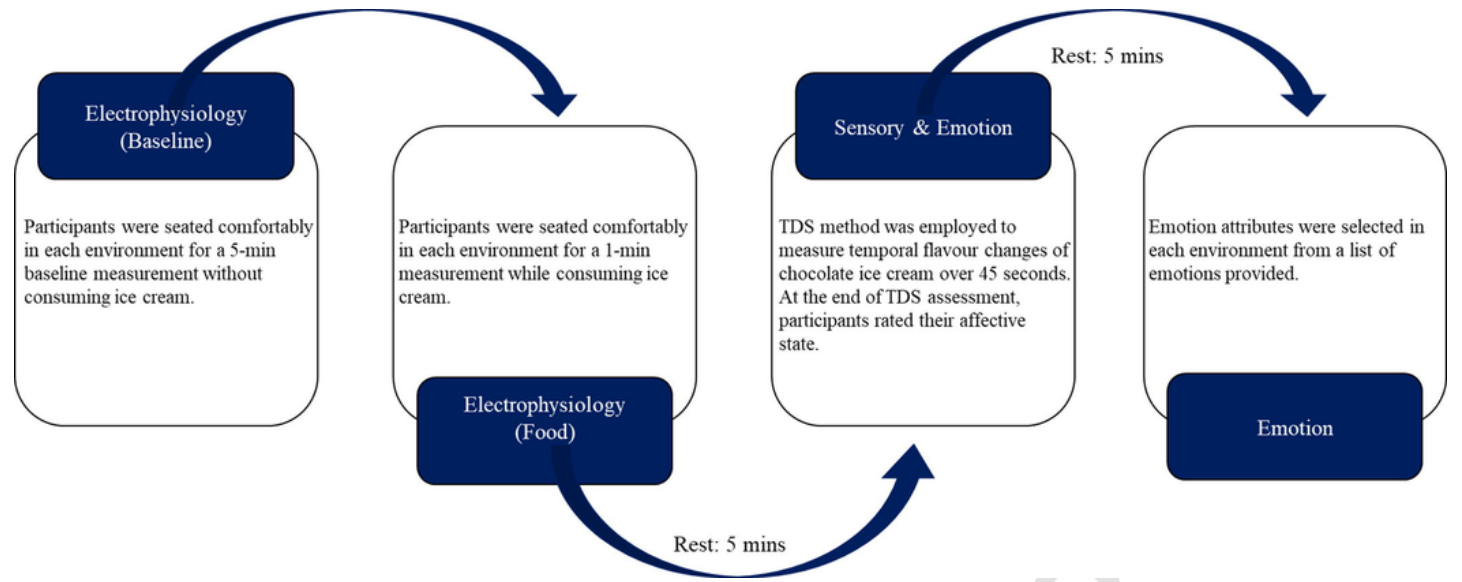

Fig. 1. Experimental design used in the present study.

a)

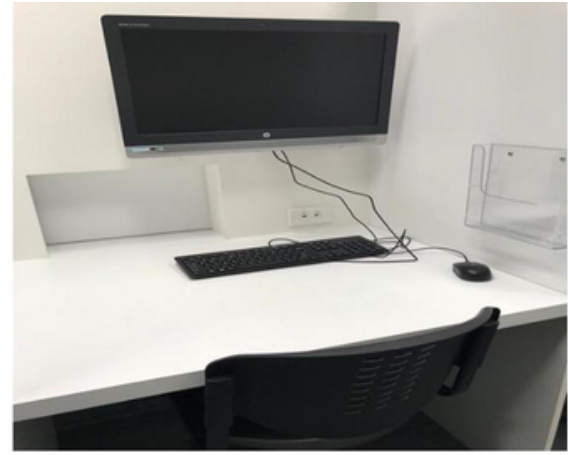

c)

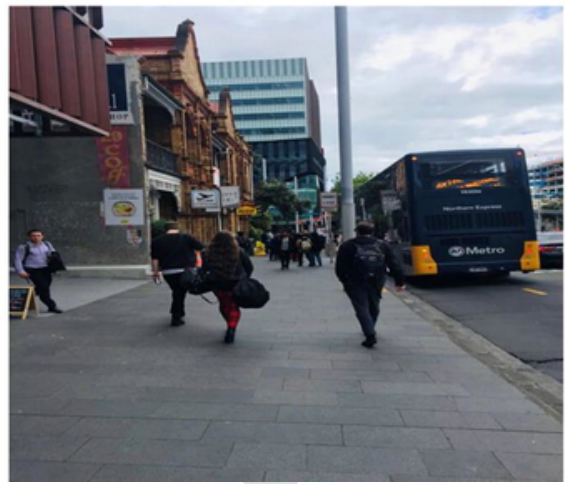

b)

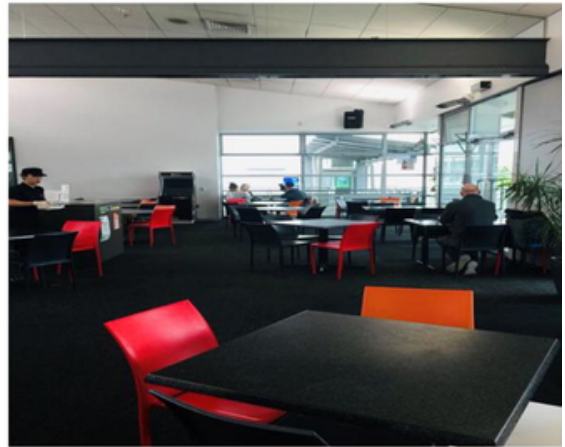

d)

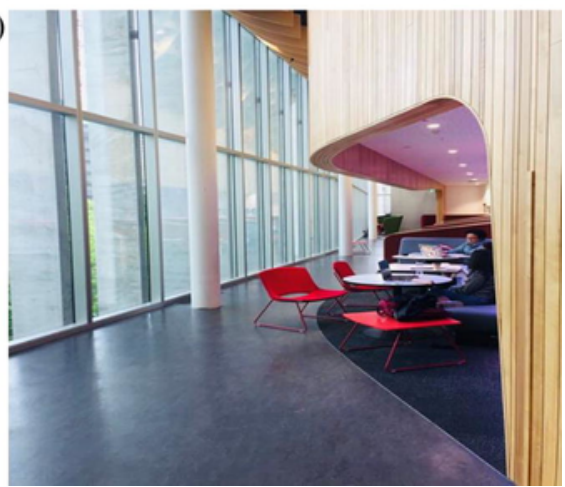

Fig. 2. The laboratory (a), café (b), bus stop (c) and university study area (d) environments where ice cream was consumed.

pants were provided with informed consent forms prior to the commencement of the study.

\subsection{Background sound recordings}

The background sounds of the different environments (i.e., laboratory, café, university study area, and bus stop) were recorded on a weekday between 11:00 a.m. and 12:00p.m. using a Sennheiser microphone (Series HD 518: Sennheiser Electronics GmbH and Co. KG, Wedemark, Germany) connected to a standard PC sound card. Subsequently, psychoacoustical parameters (tonality, sharpness, roughness, and fluctuation strength) were calculated to characterise the soundscape of each environment (Fastl \& Zwicker, 2007). Here, tonality measures the relative content of pure tones, sharpness the relative content of high frequencies, roughness the modulation within low frequencies $(15-300 \mathrm{~Hz})$, and fluctuation strength the amplitude modulation of the recorded soundscapes. National Instruments LabVIEW 2013 software (Austin, TX, USA) was used to calculate the psychoacoustical parameters using its inbuilt sound quality module.

\subsection{Sample preparation and presentation}

The chocolate ice cream samples were made up of $60 \%$ cream, $16 \%$ milk, $15.7 \%$ sugar, $8 \%$ cocoa powder, and $0.3 \%$ vanilla extract. An ICE-100 ice cream and gelato maker (Cuisinart, America) was used to make chocolate ice cream. A scoop of chocolate ice cream $(5 \pm 0.8 \mathrm{~g})$ was placed in individual portion cups ( $45 \mathrm{~mm}$ diameter) and frozen in a commercial-grade freezer (Fisher and Paykel, NZ) at $-18^{\circ} \mathrm{C}$ for at least $24 \mathrm{~h}$ prior to serving to ensure sample consistency. All of the samples were thawed for at least two minutes at room temperature before serving. The serving temperature $\left(-12 \pm 2{ }^{\circ} \mathrm{C}\right)$ was strictly controlled to maintain consistency. 


\subsection{Participants}

One hundred and sixty participants (50 males, 110 females) aged between 20 and 40 years old were recruited in this study. A between-participants design involved forty participants consuming ice cream samples in different eating environments (laboratory ( 7 males, 33 females), bus stop (13 males, 27 females), café (19 males, 21 females), and university study area (10 males, 30 females)). Forty participants were chosen to carry out the experiments in each environment in order to achieve a statistical power of $0.90-0.95$ using the Cohen's d calculation of 0.8 (Kenny, 1987) as used in our previous research (see Kantono, Hamid, Shepherd, Yoo, et al., 2016; Kantono, Hamid, Shepherd, Lin, et al., 2016; Kantono, Hamid, Shepherd, Yoo, Carr, et al., 2016). The participants were recruited by advertisements placed around the university, and were excluded if they smoked, or reported any health problems. The study was carried out any time between 11:00 am and 2:00 pm, to ensure that all participants completed the experiment before lunch.

\subsection{Temporal dominance of sensation (TDS) training}

Participants first underwent a 15-min training session dedicated to the TDS method. First, the participants were introduced to the concept of dominance defined as the sensory sensation of food that directed the participant's attention at any given time. The participants were instructed that dominance might switch if a new sensation arrived (Labbe, Schlich, Pineau, Gilbert, \& Martin, 2009; Pineau et al., 2009). Furthermore, the intensity of the dominant attribute was rated by participants using an unstructured line scale anchored with "none" and "extreme" (Pineau et al., 2009). The participants were also familiarized with the measure of flavour sensations of ice cream using TDS through exposure to a dummy TDS trial during training.

\subsection{TDS analysis}

TDS was used to capture the temporal flavour changes in ice cream flavour as described by Pineau et al. (2009). Selected sensory attributes (cocoa, milky, creamy, vanilla, roasted, sweet, and bitter) were measured using an unstructured line scale with anchors labelled with "none" and "extreme" at each end (Kantono, Hamid, Shepherd, Yoo, et al., 2016). For each eating environment, a TDS session lasted for $45 \mathrm{~s}$. The TDS screenshot of what participants viewed when they carried out the experiment in this study is shown in Fig. 3. All sensory data acqui- sition was undertaken by using the FIZZ Acquisition software (v. 2.46b: Biosystemes, France).

\subsection{Emotional responses in different eating environments}

The Self-Assessment Manikin (SAM) as described by Bradley and Lang (1994) was used in this study to analyse participants' affective responses after consuming ice cream in the different eating environments. Table 1 summarizes the definitions of valence, arousal, and dominance. The SAM emotion attributes were measured using a $15 \mathrm{~cm}$ unstructured line scale with anchors labelled using the labels shown in Table 1.

The participants also had to select emotional attributes after consuming the ice cream. A list of twenty emotions were obtained from a focus group of 40 participants who selected the emotions that they experienced in different environments (laboratory, café, bus stop, and university study area) from the Profile of Mood States Questionnaire (McNair, Lorr, \& Droppleman, 1971), Multiple Affect Adjective Checklist-Revised (Lubin \& Zuckerman, 1999), Positive and Negative Affect Schedule (Watson, Clark, \& Tellegen, 1988) and Geneva Affect Label Coder (Scherer, 2005). The participants selected emotions from the check-all-that-apply (CATA) emotion questionnaire provided while eating ice cream in the different environments. The emotions provided are shown in Table 2.

\subsection{Electrophysiological measures}

Standard electrophysiological measures including heart rate (HR), blood volume pulse (BVP), and skin conductance (SC) were measured using a Nexus 10 device (24-bit A-D converters) and BioTrace + software (version V2011B1. 2004-2010 Mind Media B.V. Roermond, NL). The BioTrace + software was used to analyse the obtained electrophysiological data. Electrodes (gelled $\mathrm{Ag} / \mathrm{AgCl}$ ) were used to measure the participant's cardiac and sweat gland activity. SC response was measured by attaching sensors to the third and fourth digits (middle phalanx) of the non-dominant hand. HR and BVP signals were recorded with the Nexus-10-Heart Rate sensor attached to the left index finger using the photoplethysmography technique.

Electrophysiological measurements were collected for a 5-min baseline without eating ice cream, and a further one-minute while eating chocolate ice cream $(5 \pm 0.8 \mathrm{~g})$. With the five minutes baseline measurement, participants were seated in a relaxed and upright position, and were asked not to move their non-dominant hand during the experiment. All of the signals were recorded at a data sampling rate of 32 data samples per second using the BioTrace + software.

Sensory Testing of Chocolate Ice Cream

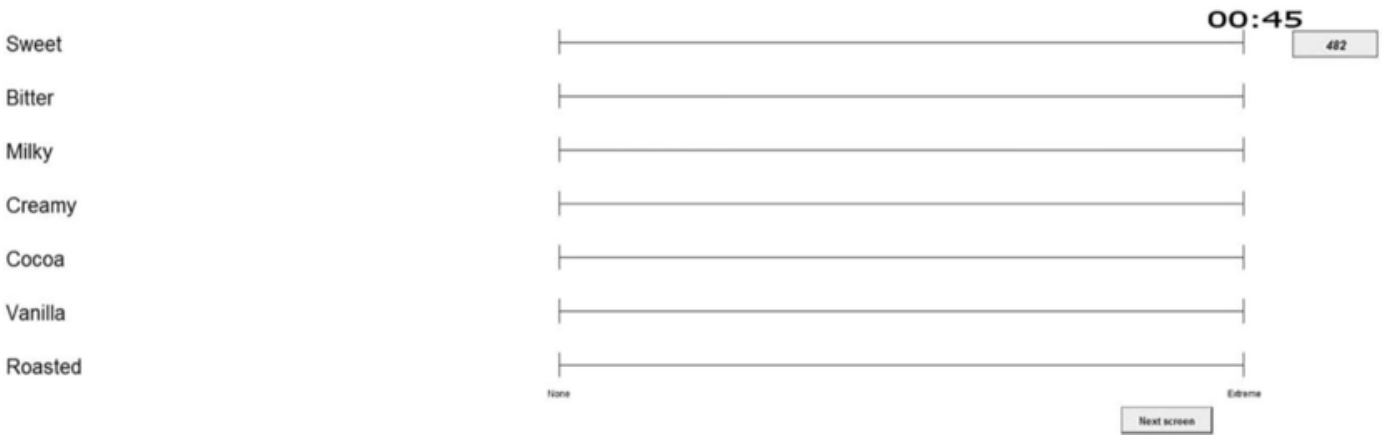

Fig. 3. The TDS assessment screen as used by participants. 
Table 1

Description of the Self-Assessment Manikin affect attributes provided to participants.

\begin{tabular}{|c|c|c|c|}
\hline $\begin{array}{l}\text { Affect } \\
\text { attributes }\end{array}$ & Description & Anchors & Reference \\
\hline Valence & $\begin{array}{l}\text { The } \\
\text { pleasantness of } \\
\text { the stimulus }\end{array}$ & $\begin{array}{l}\text { From } \\
\text { 'unpleasant' to } \\
\text { 'pleasant' }\end{array}$ & $\begin{array}{l}\text { Soleymani, Chanel, } \\
\text { Kierkels, \& Pun, 2008; } \\
\text { Warriner, Kuperman, \& } \\
\text { Brysbaert, } 2013\end{array}$ \\
\hline Arousal & $\begin{array}{l}\text { The intensity of } \\
\text { emotion } \\
\text { provoked by the } \\
\text { stimulus }\end{array}$ & $\begin{array}{l}\text { From 'calm' to } \\
\text { 'exciting' }\end{array}$ & $\begin{array}{l}\text { Soleymani et al., 2008; } \\
\text { Warriner et al., } 2013\end{array}$ \\
\hline Dominance & $\begin{array}{l}\text { The degree of } \\
\text { attentional } \\
\text { control exerted } \\
\text { by the stimulus }\end{array}$ & $\begin{array}{l}\text { From 'not } \\
\text { controlling } \\
\text { attention' to } \\
\text { 'controlling } \\
\text { attention' }\end{array}$ & Warriner et al., 2013 \\
\hline
\end{tabular}

Table 2

The list of emotions used in this study.

\begin{tabular}{|c|c|c|c|}
\hline $\begin{array}{l}\text { Emotion } \\
\text { attribute }\end{array}$ & Valence & Source & Reference \\
\hline $\begin{array}{l}\text { Unable to } \\
\text { concentrate }\end{array}$ & Negative & $\begin{array}{l}\text { Profile of Mood States } \\
\text { Questionnaire }\end{array}$ & $\begin{array}{l}\text { McNair et al., } \\
1971\end{array}$ \\
\hline Lost & Negative & $\begin{array}{l}\text { Multiple Affect Adjective } \\
\text { Checklist-Revised }\end{array}$ & $\begin{array}{l}\text { Lubin \& } \\
\text { Zuckerman, } 1999\end{array}$ \\
\hline $\begin{array}{l}\text { Uncertain about } \\
\text { things }\end{array}$ & Negative & $\begin{array}{l}\text { Profile of Mood States } \\
\text { Questionnaire }\end{array}$ & $\begin{array}{l}\text { McNair et al., } \\
1971\end{array}$ \\
\hline Disgusted & Negative & $\begin{array}{l}\text { The Positive and Negative } \\
\text { Affect Schedule }\end{array}$ & $\begin{array}{l}\text { Watson et al., } \\
1988\end{array}$ \\
\hline Tired & Negative & $\begin{array}{l}\text { The Positive and Negative } \\
\text { Affect Schedule }\end{array}$ & $\begin{array}{l}\text { Watson et al., } \\
1988\end{array}$ \\
\hline Tense & Negative & $\begin{array}{l}\text { Profile of Mood States } \\
\text { Questionnaire } \\
\text { The Positive and Negative } \\
\text { Affect Schedule }\end{array}$ & $\begin{array}{l}\text { McNair et al., } \\
1971 \\
\text { Watson et al., } \\
1988\end{array}$ \\
\hline Composed & Negative & $\begin{array}{l}\text { Multiple Affect Adjective } \\
\text { Checklist-Revised }\end{array}$ & $\begin{array}{l}\text { Lubin \& } \\
\text { Zuckerman, } 1999\end{array}$ \\
\hline Unhappy & Negative & $\begin{array}{l}\text { Profile of Mood States } \\
\text { Questionnaire }\end{array}$ & $\begin{array}{l}\text { McNair et al., } \\
1971\end{array}$ \\
\hline Annoyed & Negative & $\begin{array}{l}\text { The Positive and Negative } \\
\text { Affect Schedule } \\
\text { Multiple Affect Adjective } \\
\text { Checklist-Revised }\end{array}$ & $\begin{array}{l}\text { McNair et al., } \\
1971 \\
\text { Watson et al., } \\
1988\end{array}$ \\
\hline Anxious & Negative & $\begin{array}{l}\text { Profile of Mood States } \\
\text { Questionnaire }\end{array}$ & $\begin{array}{l}\text { McNair et al., } \\
1971\end{array}$ \\
\hline Cheerful & Positive & $\begin{array}{l}\text { The Positive and Negative } \\
\text { Affect Schedule }\end{array}$ & $\begin{array}{l}\text { Watson et al., } \\
1988\end{array}$ \\
\hline Calm & Positive & $\begin{array}{l}\text { The Positive and Negative } \\
\text { Affect Schedule }\end{array}$ & $\begin{array}{l}\text { Watson et al., } \\
1988\end{array}$ \\
\hline At ease & Positive & $\begin{array}{l}\text { The Positive and Negative } \\
\text { Affect Schedule }\end{array}$ & $\begin{array}{l}\text { Watson et al., } \\
1988\end{array}$ \\
\hline Concentrating & Positive & $\begin{array}{l}\text { The Positive and Negative } \\
\text { Affect Schedule }\end{array}$ & $\begin{array}{l}\text { Watson et al., } \\
1988\end{array}$ \\
\hline Joy & Positive & $\begin{array}{l}\text { The Geneva Affect Label } \\
\text { Coder }\end{array}$ & Scherer, 2005 \\
\hline Pleasure & Positive & $\begin{array}{l}\text { The Geneva Affect Label } \\
\text { Coder }\end{array}$ & Scherer, 2005 \\
\hline Satisfied & Positive & $\begin{array}{l}\text { Profile of Mood States } \\
\text { Questionnaire }\end{array}$ & $\begin{array}{l}\text { McNair et al., } \\
1971\end{array}$ \\
\hline Excited & Positive & $\begin{array}{l}\text { The Positive and Negative } \\
\text { Affect Schedule }\end{array}$ & $\begin{array}{l}\text { McNair et al., } \\
1971\end{array}$ \\
\hline Positive & Positive & $\begin{array}{l}\text { The Geneva Affect Label } \\
\text { Coder }\end{array}$ & Scherer, 2005 \\
\hline Happy & Positive & $\begin{array}{l}\text { The Positive and Negative } \\
\text { Affect Schedule } \\
\text { Multiple Affect Adjective } \\
\text { Checklist-Revised }\end{array}$ & $\begin{array}{l}\text { Watson et al., } \\
1988 \\
\text { Lubin \& } \\
\text { Zuckerman, } 1999\end{array}$ \\
\hline
\end{tabular}

\subsection{Data analysis}

\subsubsection{TDS curve}

In this study, TDS dominance curves were used to exhibit the dominance ratings of all attributes over time by using in-built spline-based smoothing algorithm in the FIZZ software (Pineau et al., 2009). Temporal dominance curves display the percentage of participants who recognised the prescribed attributes as being dominant at a given time (Pineau et al., 2009). TDS time was presented as standardized time (ST), and data was converted to percentages (0-100\%) (Ares et al., 2015). The significant $\left(\mathrm{P}_{\mathrm{s}}\right)$ and the chance $\left(\mathrm{P}_{0}\right)$ levels were determined from the panel curves, and calculated according to Pineau et al. (2009).

\subsubsection{Canonical variate analysis}

Canonical Variate Analysis (CVA) was performed on emotion and flavour perception data. CVA minimizes residual variability and maximizes the distances between samples (Delarue \& Sieffermann, 2004), and carried out using XLSTAT (version 2018.5) (Addinsoft, USA). Additionally, Multivariate Analysis of Variance (MANOVA) tests were used to determine if significant differences existed between the four eating environments in terms of standardized durations of flavour $(\alpha=0.05)$.

\subsubsection{TDS trajectory plots}

Principal component analysis (PCA) was carried out on the dominance rates of every dominant attribute, over time, after consuming chocolate ice cream by using XLSTAT (Version 2018.5) (Addinsoft, USA). The PCAs were used to provide a global representation of the trajectory of environmental condition in relation to the evolution of each dominance in flavour perception based on the first and second principal components. The dominant flavour trajectories in each environment are illustrated by connecting the time points graphically (from the initial score $\left(\mathrm{t}_{0}\right)$ to the last $\left(\mathrm{t}_{100}\right)$ point). The time points were $0 \%$, $10 \%, 20 \% \ldots 100 \%$ of the TDS standardized time (Saint-Eve, Panouille, Capitaine, Deleris, \& Souchon, 2015), with a total of 11 standardized time points for each environment.

\subsubsection{Analysis of emotion responses}

Cochran's Q test was used to analyze the frequencies of emotional responses in the different environments using XLSTAT (Version 2018.5) (Addinsoft, USA). The emotional data was dichotomised (0: not selected, 1: selected). Multiple pairwise comparisons using the Marascuilo procedure were applied for analyses that reached statistical significance $(\alpha=0.05)$ (Addinsoft, USA).

\subsubsection{Electrophysiological measurement}

Prior to analysis, Grubb's test was performed to remove outliers from the electrophysiology data. Average values of electrophysiological indices (i.e., BVP, SC and HR) were calculated with reference to a five-minute baseline measurement. The percentage change from baseline was calculated according to Zhang and Han (2009):

Percentage change (\%)

$=\frac{(\text { raw value }- \text { mean baseline value })}{\text { mean baseline value }} \times 100$

A one-way ANOVA was carried out in order to investigate significant differences for the percentage change in electrophysiological measures while consuming ice cream in the different environments. In addition, a two-way ANOVA was carried out on the percentage change in electrophysiological measurements in the different environments and gender effects as factors. This enabled us to explore gender effects for the electrophysiological measures obtained when participants consumed ice cream in the different environments as genetically-deter- 
mined individual differences may exist in flavour perception between men and women (though see Spence, 2019, for a recent review). The Tukey post-hoc comparisons tests were used when significance was found (Addinsoft, USA).

\subsubsection{Multiple factor analysis}

Multiple Factor Analysis (MFA) enables the simultaneous analysis of several sets of variables in order to study the relationship between the samples (observations) and dependent variables. In this study, MFA was applied to the TDS sensory duration measures, as well as emotional CATA responses and ANS measures obtained from this study. This allowed the relationship between the sensory responses to emotion and ANS measurements to be further explored.

\section{Results}

\subsection{Psychoacoustic characteristics of the soundscapes}

The psychoacoustical characteristics of sounds in the different eating environments are presented in Table 3 . The café soundscape had the highest sharpness, tonality, and fluctuation strength values as compared to the bus stop, university study area and laboratory environments. In addition, the bus stop soundscape had the highest roughness followed by café, laboratory and the university study area environments.

Table 3

Psychoacoustic parameters of sounds in the lab, café, university study area, and bus stop environments.

\begin{tabular}{lllll}
\hline $\begin{array}{l}\text { Psychoacoustic } \\
\text { parameters }\end{array}$ & $\begin{array}{l}\text { Bus } \\
\text { stop }\end{array}$ & Café & Lab & $\begin{array}{l}\text { University study } \\
\text { area }\end{array}$ \\
\hline $\begin{array}{l}\text { Sharpness (acum) } \\
\text { Roughness (asper) }\end{array}$ & 2.27 & 2.35 & 1.1 & 1.59 \\
$\begin{array}{c}\text { Fluctuation Strength } \\
\quad(\text { vacil) }\end{array}$ & 0.14 & 0.0018 & 0.00031 & 0 \\
$\quad$ Tonality (sone) & 0 & 2.50 & 0.14 & 1.66 \\
\hline
\end{tabular}

(a)

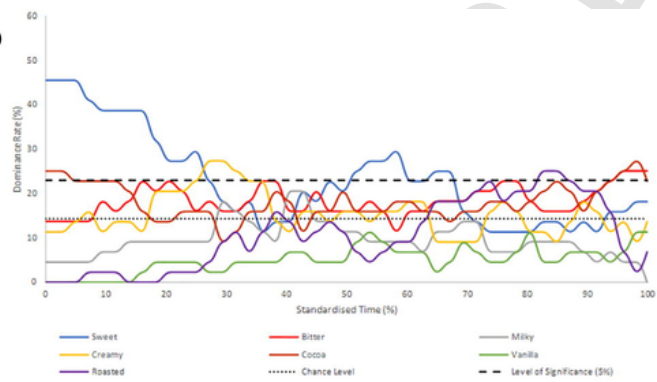

(c)

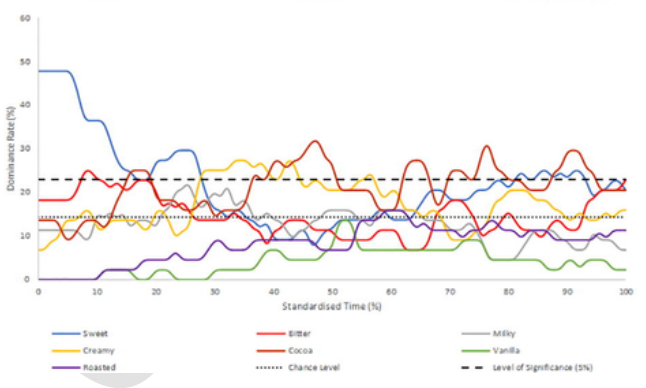

\subsection{Temporal dominance of sensations}

Fig. 4 depicts the spline smoothed TDS curves describing the dominance rate of various ice cream attributes as consumed in the different environments. The calculated chance and significance levels were between $15 \%$ and $20 \%$, respectively. Attributes below 20\% (re: significance level) will not be discussed further here. It can be seen that although sweetness was the first dominant attribute in all four environments, its dominance varied over time.

For the laboratory environment, a longer and higher duration of sweetness was evident, with a maximum dominance rate of $46 \%$ at the start mastication that became less dominant until 26\% ST. Creaminess was dominant from 26 to $37 \%$ ST, with a maximum rate of $28 \%$ at $30 \%$ ST. Sweetness then again became dominant from 50 to $67 \%$ ST. Roasted was dominant from 81 to $87 \%$ ST, reaching a maximum dominance of $25 \%$ at $84 \%$ ST. Finally, cocoa was dominant from $92 \%$ ST until the end of the measurement.

In the university study area, sweetness was dominant at the start and slowly decreased from a maximum dominance rate of $33 \%$ between 0 and $9 \%$ ST. Milky was dominant from 9 to $15 \%$ ST, reaching a maximum dominance of $31 \%$ at $13 \%$ ST. Cocoa had a higher dominance rate and longer duration from 19 to $73 \%$ ST as compared to the control laboratory environment, reaching a maximum rate of $38 \%$ at $25 \%$ ST.

Sweetness was dominant from 0 to $28 \%$ ST, reaching a maximum rate of $48 \%$, and creaminess was dominant from $28 \%$ ST to $38 \%$ ST, with a maximum rate of $28 \%$ at $34 \%$ ST in the café similar to the laboratory environment. However, cocoa was observed to be the dominant attribute at several evaluation points after 38\% ST in the café, which was different from other environments. It was dominant from $38 \%$ ST to $52 \%$ ST, 60 to $80 \%$ ST, and 87 to $93 \%$ ST reaching a maximum rate of $32 \%$ at $49 \%$ ST, at $76 \%$ ST, and $30 \%$ at $90 \%$ ST, respectively.

At the bus stop, sweetness was dominant at the start and slowly decreased from a maximum dominance rate of $38 \%$ between 0 and $10 \%$ ST similar to the laboratory. However, bitterness was the dominant attribute thereafter at several points of evaluation different to the other three environments. It was dominant between 10-30\% ST and 36-79\% ST, reaching a maximum rate of $38 \%$ at $35 \%$ ST, and $30 \%$ at 42,58

(b)

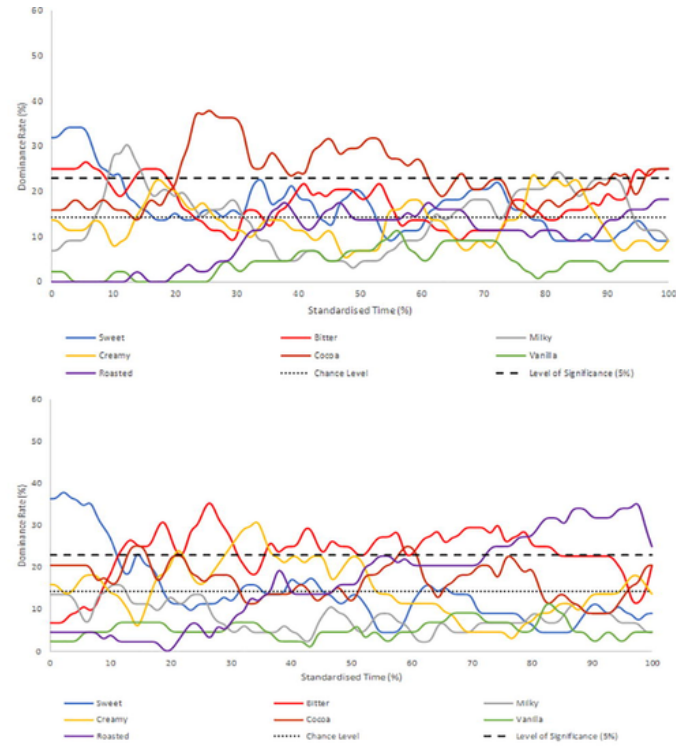

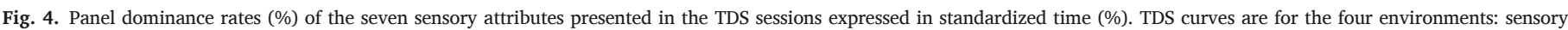
laboratory (control) (a), university study area (b), cafe (c), and bus stop (d). 
and 74\% ST. Roasted was dominant from 79\% ST to the end of the evaluation, with a maximum dominance rate of $35 \%$ at $98 \%$ ST.

\subsection{Flavour trajectories of chocolate ice cream in different environments}

A series of PCAs were undertaken to further understand and compare the dominance rate of sensory perception during the standardized time from the beginning of flavour perception and the time of swallowing ice cream in the different environments. The first two PCA components represented $52.57 \%$ of the total variance observed between samples (see Fig. 5). For each of four environments, a trajectory of perceived dominant attributes was shown. Sweetness was always the first perceived attribute in the laboratory, university study area, bus stop, and cafe environments at $20 \%, 7 \%, 12 \%$, and $20 \%$ of the trajectory ST, respectively. This finding agrees with the TDS sensory profile results shown in Fig. 4. In the café environment, milkiness and cocoa were at $32 \%$ and $58 \%$ of the trajectory time, respectively. Creamy and sweet flavours were then perceived at the end of mastication, at $94 \%$ and $96 \%$ of the trajectory time, respectively, in the café. In the study space, roasted, vanilla and cocoa were perceived after sweetness, at $45 \%, 50 \%$, and $69 \%$ of the trajectory times, respectively. In the laboratory, creamy and cocoa flavours were perceived at $45 \%$ and $48 \%$ of the trajectory times respectively. Cocoa, vanilla and roasted were further perceived at $72 \%, 74 \%$, and $86 \%$ of the trajectory times, respectively. In the bus stop environment, bitter was mainly perceived at $22 \%, 38 \%$ and $45 \%$ of the trajectory times.

\subsection{Relationship between perception of ice cream and different eating environments}

Canonical variate analysis was used to further summarize the standardized duration of flavour perception when ice cream was consumed in different environments. Fig. 6 describes the first two canonical variates which explained $95.20 \%$ of the data. The $90 \%$ ellipse represents the multidimensional confidence intervals of means (Peltier, Visalli, \& Schlich, 2015) of the standardized duration of flavour. The separation of the ellipses suggests that the flavour depended upon the environment in which the ice cream was consumed.

The Hotelling-Lawley MANOVA analysis results showed significant differences between the standardized duration of flavour perception of chocolate ice cream in the four eating environments $\left(F_{(7,168)}=2.682\right.$, $p<0.05$ ). The laboratory was only associated with the creamy attribute, and the café was related to sweet taste. The study space was associated with milky and cocoa flavours, while the bus stop environment was related to roasted and bitter flavours.

\subsection{Affective dimensions}

Participants rated the affective dimensions of the four different environments after consuming ice cream. Fig. 7 shows that the four eating environments were judged to be significantly different in terms of their valence, arousal, and dominance.

The bus stop environment was rated significantly lower in terms of valance, arousal, and dominance compared to the laboratory, café, and university study area. The university study area and cafe were significantly higher in terms of valence and arousal, respectively, when compared to the bus stop environment.

\subsection{Emotion responses in the different eating environments}

All the selected emotions listed in Table 4 were based on a pilot trial carried out using 97 participants in four different environments (sensory laboratory, bus stop, café, and study space) in the vicinity of Auckland University of Technology. The pilot trial revealed that the

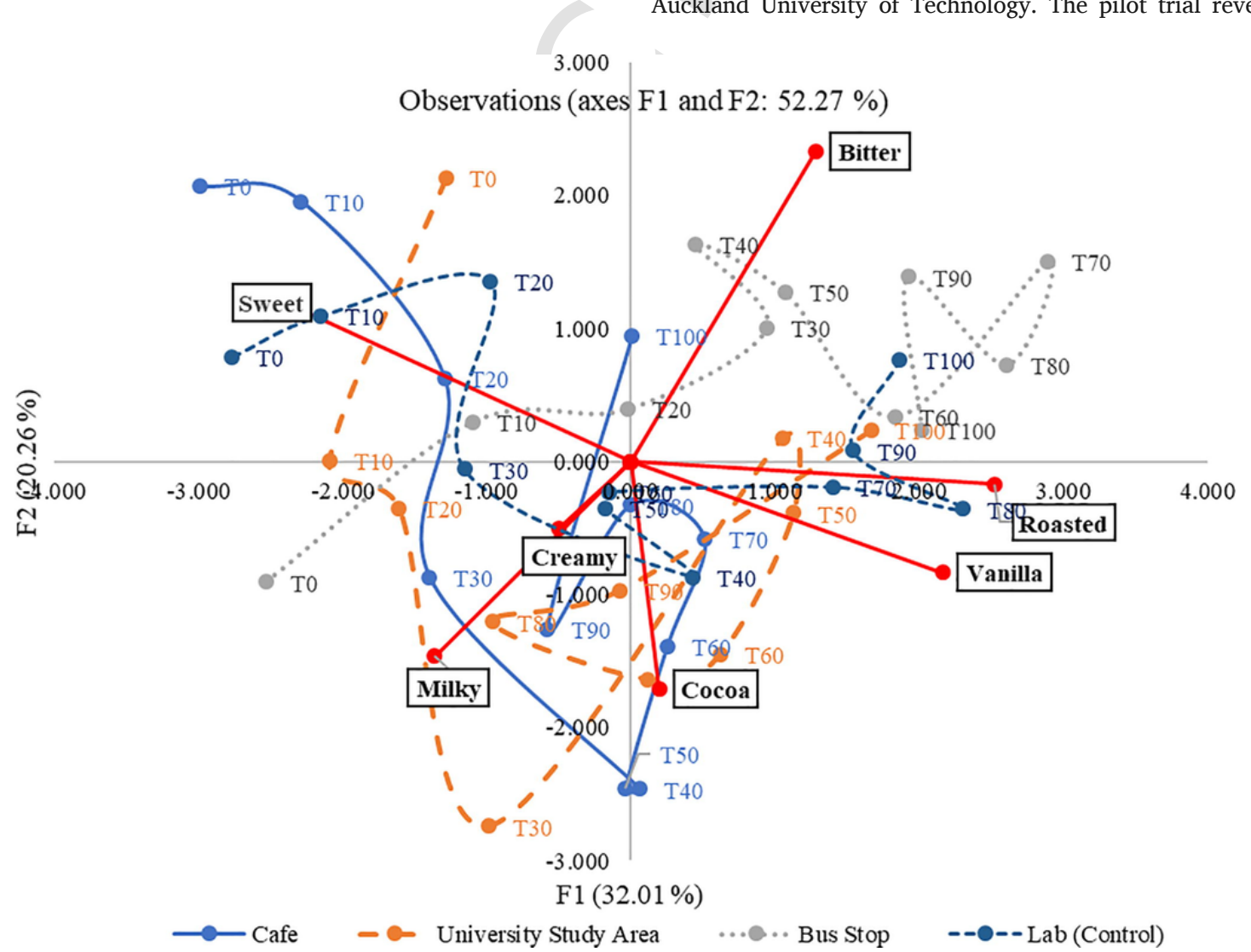

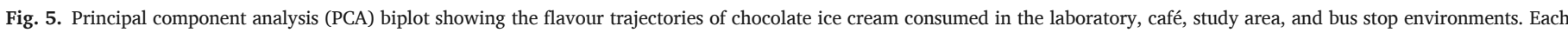
point represents $10 \%$ TDS standardized trajectory period (e.g., T0: 0\% ST; T100: 100\% ST). 


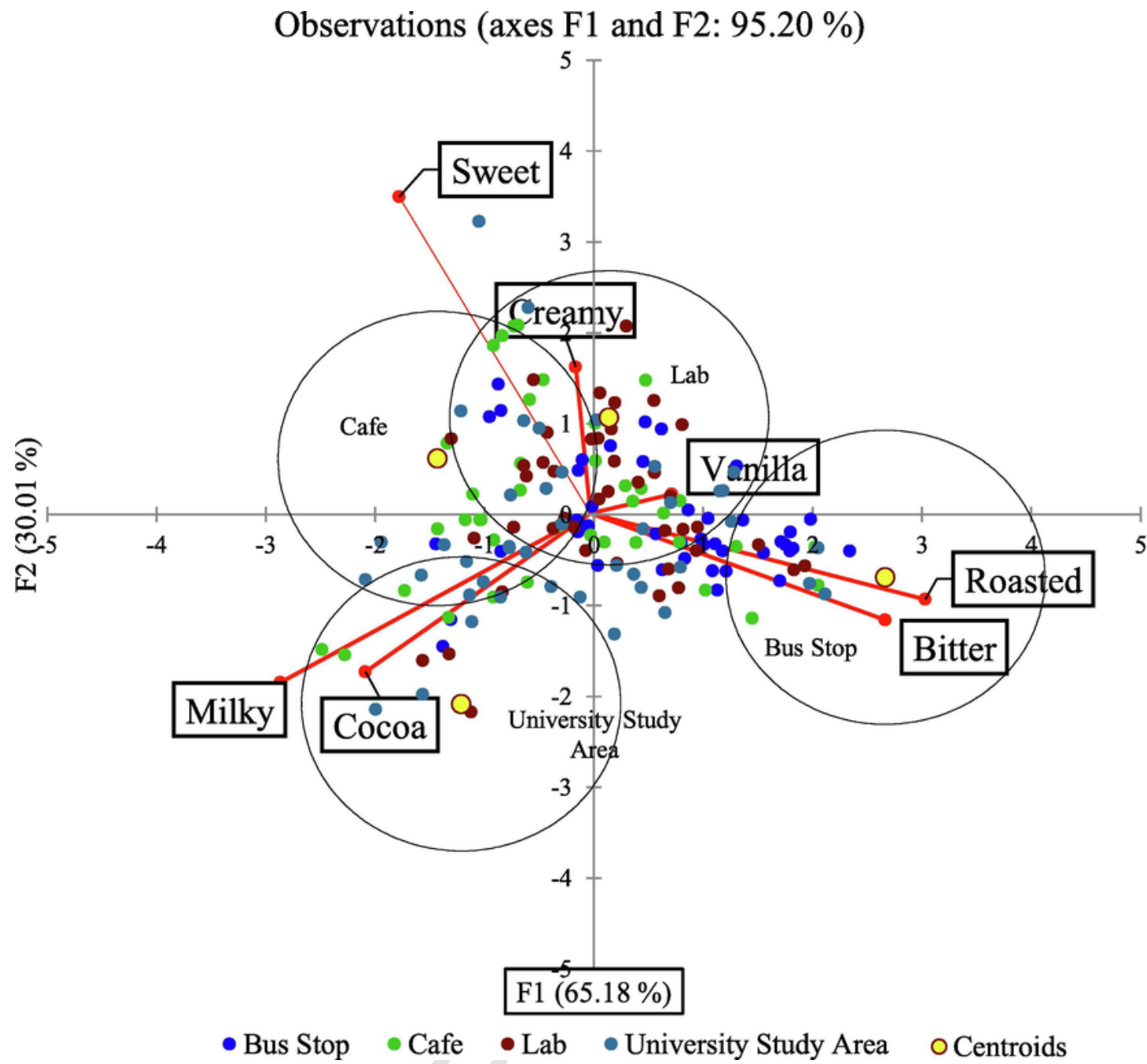

Fig. 6. Canonical Variate Analysis biplot of dominance durations of sensations. Hotelling-Lawley MANOVA test showed significant product differences based on sensory attributes.

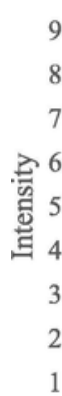

1

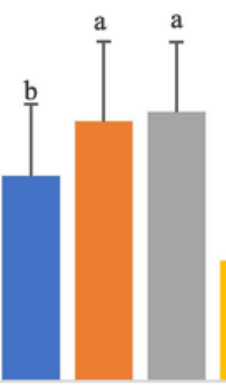

Valence

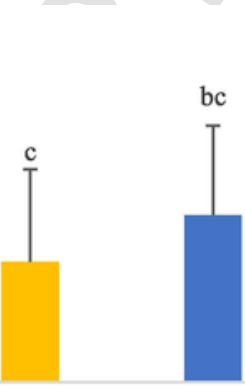

Arousal

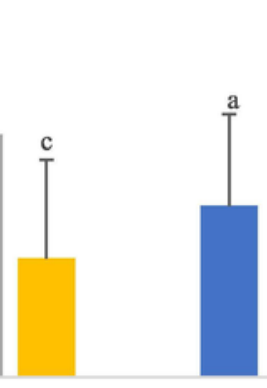

Dominance

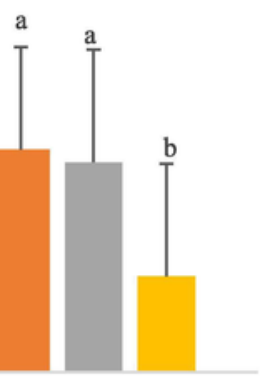

Affective Dimensions

alab University Study Area $\quad$ Café $\quad$ Bus Stop

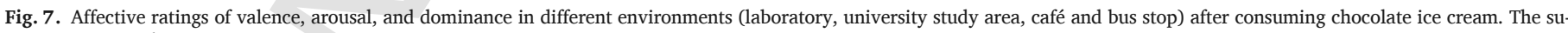

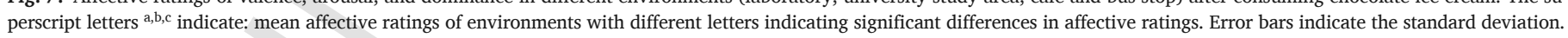

university study area was associated with the highest number of positive emotions followed by the café, laboratory and bus stop. The bus stop. on the other hand, had the highest number of negative emotions attributed to it.

The frequencies of the emotion responses expressed by the participants revealed significant differences between the four environments (see Table 4) where different superscripts denote significant differences of each emotion in different environment. Frequency of the concentrat- ing attribute was significantly higher in the laboratory environment as compared to the university study area and bus stop environments. Frequencies of positive emotions of happy, positive, pleasure, joy, at ease and cheerful were significantly higher in the café and university study area environments as compared to the bus stop environment. On the other hand, frequencies of negative emotions of unable to concentrate, uncertain about things, negative, tired, tense, unhappy, annoyed, and anxious were significantly higher for the bus stop environment as com- 
Table 4

Self-rated emotions following the consumption of chocolate ice cream under different environments (laboratory, university study area, café, and bus stop). " represents significance using the Cochran's $\mathrm{Q}$ test for the emotion terms across the four environments. The superscripts ${ }^{\mathrm{a}, \mathrm{b}, \mathrm{c}}$ denote frequencies of emotions that are significantly different $(p<0.05)$ across the environment conditions for each emotion.

\begin{tabular}{|c|c|c|c|c|c|}
\hline Emotion & Lab & $\begin{array}{l}\text { University study } \\
\text { area }\end{array}$ & Café & $\begin{array}{l}\text { Bus } \\
\text { stop }\end{array}$ & $\mathrm{p}$ value \\
\hline $\begin{array}{l}\text { Unable to } \\
\text { concentrate }\end{array}$ & $2^{\mathrm{a}}$ & $0^{\mathrm{a}}$ & $4^{\mathrm{a}}$ & $16^{\mathrm{b}}$ & $<0.0001^{*}$ \\
\hline Lost & $1^{\mathrm{a}}$ & $13^{\mathrm{b}}$ & $0^{\mathrm{a}}$ & $2^{\mathrm{a}}$ & $<0.0001^{*}$ \\
\hline $\begin{array}{l}\text { Uncertain about } \\
\text { things }\end{array}$ & $5^{a}$ & $3^{\mathrm{a}}$ & $5^{\mathrm{a}}$ & $13^{\mathrm{b}}$ & $0.0003^{*}$ \\
\hline Negative & $0^{\mathrm{a}}$ & $0^{\mathrm{a}}$ & $0^{\mathrm{a}}$ & $12^{\mathrm{b}}$ & $<0.0001^{*}$ \\
\hline Tired & $11^{\mathrm{a}}$ & $18^{\mathrm{ab}}$ & $15^{\mathrm{a}}$ & $25^{\mathrm{b}}$ & $0.0004^{*}$ \\
\hline Tense & $12^{\mathrm{a}}$ & $11^{\mathrm{a}}$ & $2^{\mathrm{a}}$ & $26^{\mathrm{b}}$ & $<0.0001^{*}$ \\
\hline Composed & $3^{\mathrm{a}}$ & $15^{\mathrm{b}}$ & $2^{\mathrm{a}}$ & $0^{\mathrm{a}}$ & $<0.0001^{*}$ \\
\hline Unhappy & $10^{\mathrm{a}}$ & $2^{\mathrm{a}}$ & $4^{\mathrm{a}}$ & $29^{\mathrm{b}}$ & $<0.0001^{*}$ \\
\hline Annoyed & $2^{\mathrm{a}}$ & $0^{\mathrm{a}}$ & $0^{\mathrm{a}}$ & $16^{\mathrm{b}}$ & $<0.0001^{*}$ \\
\hline Anxious & $5^{\mathrm{ab}}$ & $6^{\mathrm{ab}}$ & $1^{\mathrm{a}}$ & $11^{\mathrm{b}}$ & $0.001^{*}$ \\
\hline Cheerful & $16^{\mathrm{ab}}$ & $19^{\mathrm{b}}$ & $24^{\mathrm{b}}$ & $8^{\mathrm{a}}$ & $0.001^{*}$ \\
\hline Calm & $16^{\mathrm{a}}$ & $27^{\mathrm{b}}$ & $15^{\mathrm{ab}}$ & $12^{\mathrm{a}}$ & $0.007^{*}$ \\
\hline At ease & $14^{\mathrm{a}}$ & $40^{\mathrm{b}}$ & $32^{\mathrm{b}}$ & $8^{\mathrm{a}}$ & $<0.0001^{*}$ \\
\hline Concentrating & $14^{\mathrm{a}}$ & $5^{b}$ & $7^{\mathrm{ab}}$ & $5^{b}$ & $0.018^{*}$ \\
\hline Joy & $18^{\mathrm{b}}$ & $30^{\mathrm{b}}$ & $25^{\mathrm{b}}$ & $3^{\mathrm{a}}$ & $<0.0001^{*}$ \\
\hline Pleasure & $18^{\mathrm{a}}$ & $31^{\mathrm{b}}$ & $31^{\mathrm{b}}$ & $9^{a}$ & $<0.0001^{*}$ \\
\hline Satisfied & $16^{\mathrm{a}}$ & $16^{\mathrm{a}}$ & $29^{\mathrm{b}}$ & $7^{\mathrm{a}}$ & $<0.0001^{*}$ \\
\hline Excited & $11^{\mathrm{ab}}$ & $18^{\mathrm{b}}$ & $10^{\mathrm{ab}}$ & $4^{\mathrm{a}}$ & $0.002^{*}$ \\
\hline Positive & $12^{\mathrm{ab}}$ & $17^{\mathrm{bc}}$ & $25^{c}$ & $3^{\mathrm{a}}$ & $<0.0001^{*}$ \\
\hline Happy & $17^{\mathrm{b}}$ & $37^{c}$ & $35^{c}$ & $3^{\mathrm{a}}$ & $<0.0001^{*}$ \\
\hline
\end{tabular}

pared to the laboratory and café environments after consuming chocolate ice cream.

\subsection{Relationship between emotions and different eating environments}

The results of CVA are shown in Fig. 8, with the first two canonical variates explaining $94.05 \%$ of the data. The Hotelling-Lawley MANOVA analysis results $\left(F_{(63,343)}=10.682, p<0.001\right)$ revealed significant differences between emotional responses when ice cream was consumed in the different environments. The bus stop was correlated to negative emotions of tense, tired, negative, anxious, annoyed, unhappy, unable to concentrate, and uncertain about things. The study space was correlated to the negative emotions of lost and composed, and positive emotions of calm, excited, and at ease. The café was correlated to positive emotions of joy, happy, pleasure, cheerful, positive and satisfied. The laboratory was only associated with the attribute 'concentrating'.

\subsection{Relationship between sensory and emotional responses perceived after consuming ice cream in the different eating environments}

The CVA plot in Fig. 9 depicts the relationship between the standardized duration of perceptions and the frequencies of emotional responses, obtained as ice cream was consumed in different environments. The first two canonical variates explained $93.83 \%$ of the data. The $90 \%$ confidence ellipses (Peltier et al., 2015) demonstrated that the frequencies of emotions and flavour perception of ice cream differed significantly in the four different eating environments. A Hotelling-Lawley MANOVA results showed significant differences $\left(F_{(84,336)}=8.433\right.$, $p<0.001$ ) between perceptual and emotional responses by those consuming ice cream in the different environments. The positive emotions of happy, pleasure, joy, cheerful, positive and satisfied were associated with sweet flavour in the café environment. In contrast, the negative emotions of tense, tired, anxious, negative, annoyed, unable to concentrate, unhappy, and uncertain about things were associated with bitter and roasted flavours at the bus stop. In addition, concentrating was related to creamy flavour in the laboratory environment. Finally, the positive emotions of calm, at ease, and excited, and negative emotions of lost and composed, were associated with cocoa and milky in the university study area environment.

\subsection{The effect of eating ice cream in different environments upon electrophysiological responses}

Consuming ice cream in the different eating environments significantly influenced SC $\left(F_{(3,156)}=3.149, \quad p<0.05\right)$ and HR $\left(F_{(3,156)}=2.673, p<0.05\right)$. Fig. 10 reveals that SC increased significantly when eating ice cream in the study space as compared to the laboratory. HR was significantly lower in the study space compared to the bus stop after consuming ice cream. No significant difference was found in BVP amplitude $\left(\mathrm{F}_{(3,156)}=0.202, \mathrm{p}>0.05\right)$ when eating ice cream in each of the different environments.
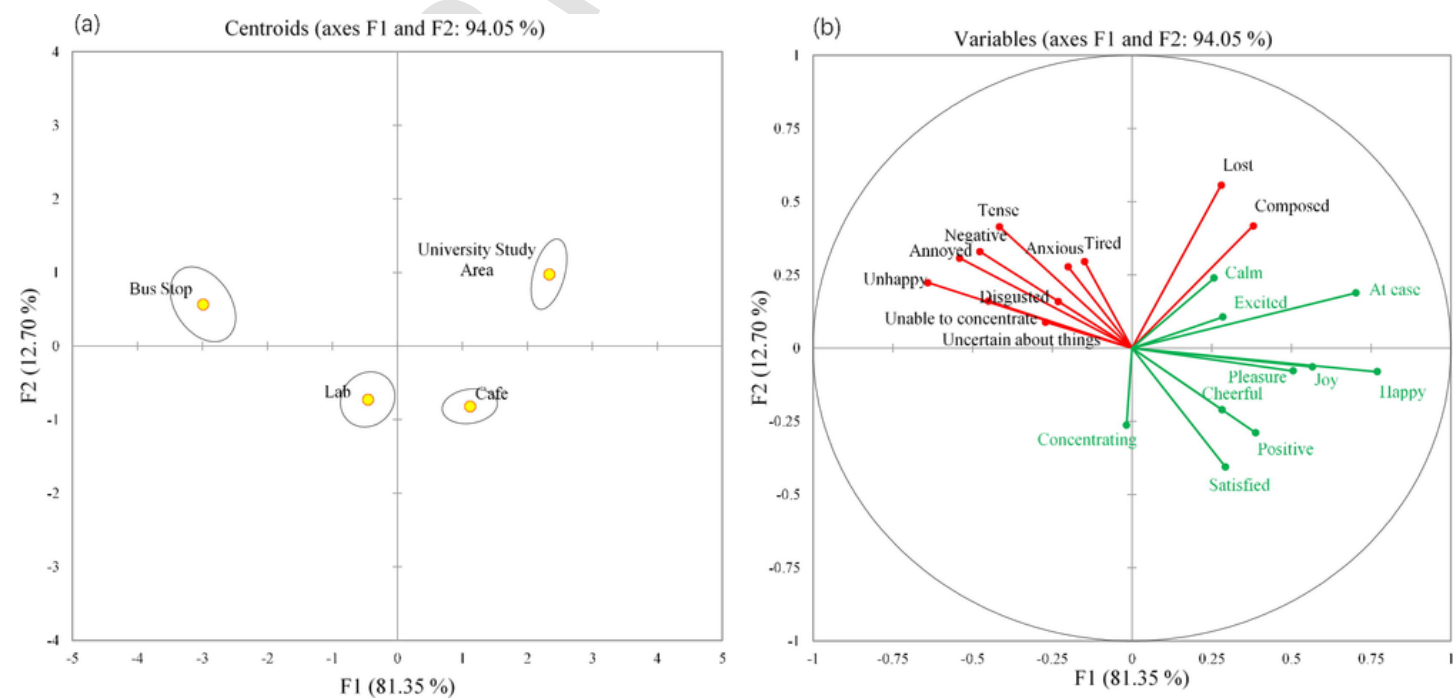

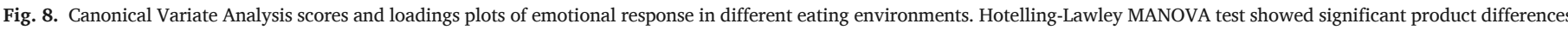

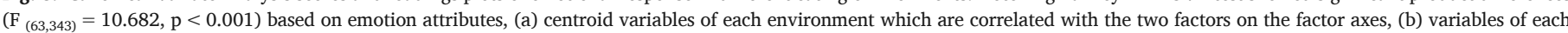

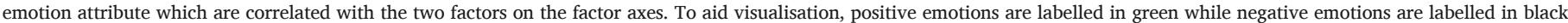
(for interpretation of the references to colour in this figure legend, the reader is referred to the web version of this article). 

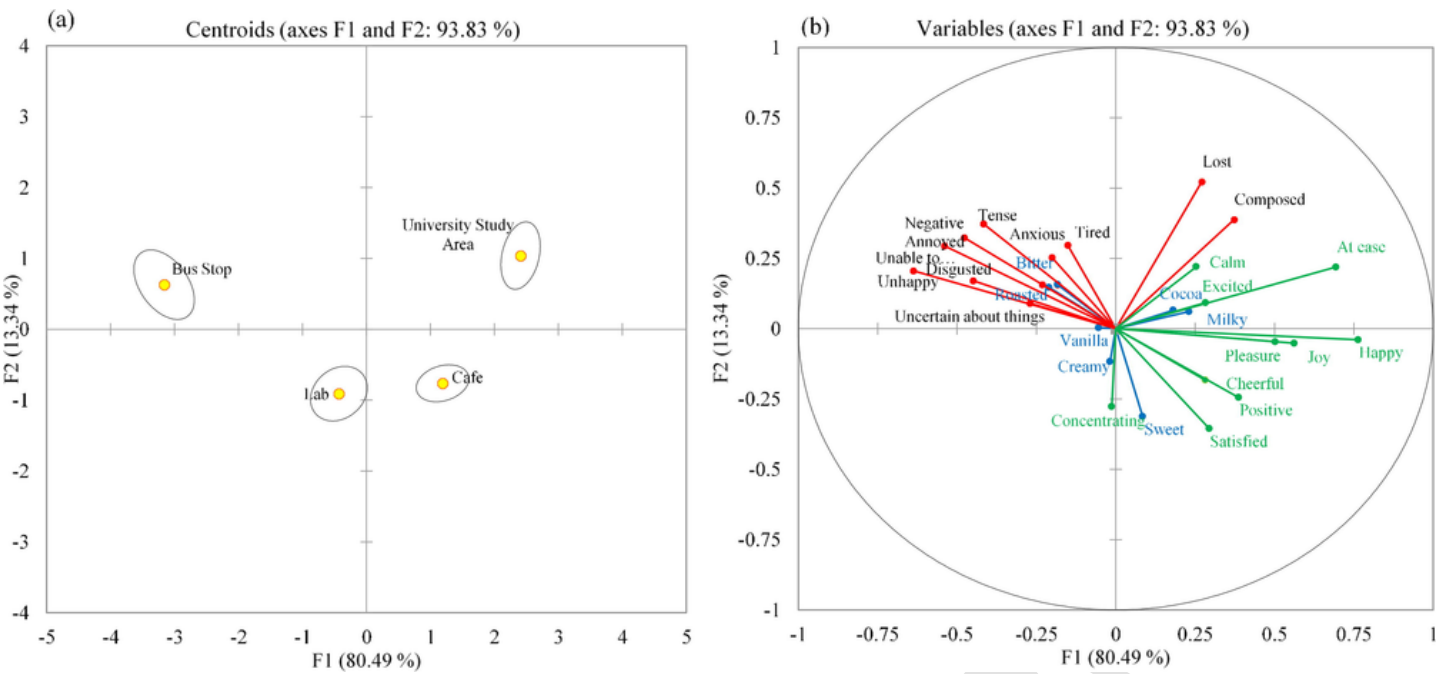

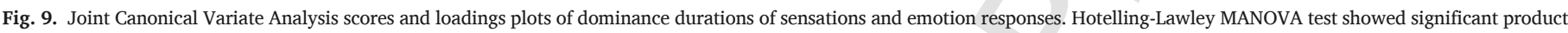

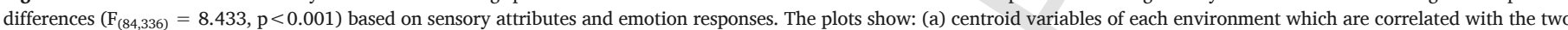

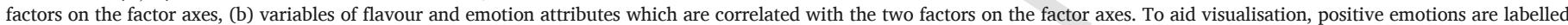

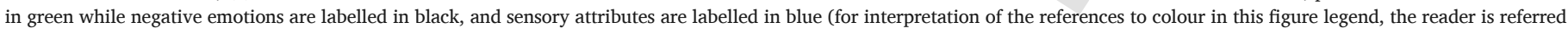
to the web version of this article).

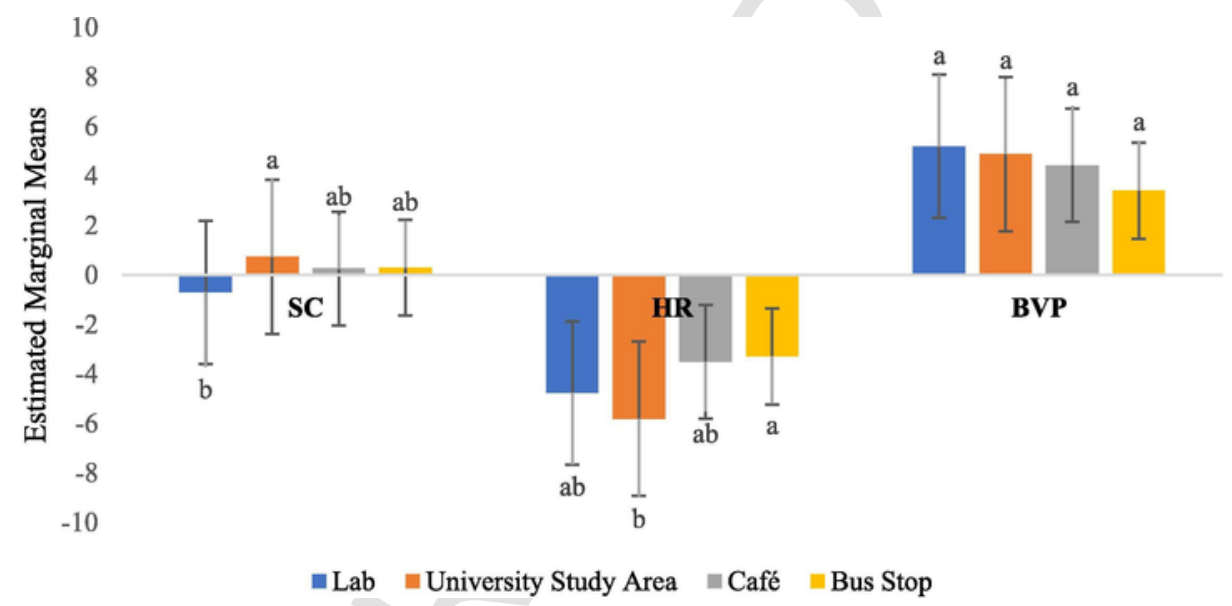

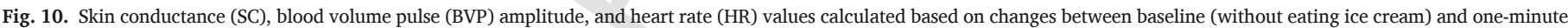

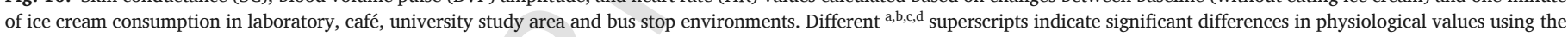
Tukey's multiple comparison tests. The error bars reflect the standard deviations of electrophysiological measurements for each environment.

\subsection{Relationship between sensory, emotion, and ANS measures perceived} after consuming ice cream in the different eating environments

MFA was used in this study to further understand the relationship between sensory, emotion, and ANS measures in this study. The MFA model further illustrates the relationship of these measures when ice cream was consumed in different eating environments. Eating ice cream in the bus stop environment elicited bitterness and roasted perceptions that were associated with negative emotions, and the electrophysiology measure of SC. On the other hand, eating ice cream the cafe environment elicited sweetness, cocoaness, and milkiness perception that was associated with positive emotions and BVP measure. Additionally, eating ice cream in the university study area elicited cocoa and milky perceptions that were associated with positive emotions, and HR measure.
3.11. The influence of gender on electrophysiological responses in different eating environment

Two-way ANOVA showed a significant main effect for gender and environment on $\mathrm{HR}\left(\mathrm{F}_{(7,152)}=3.153, \mathrm{p}<0.01\right)$, but not for SC and BVP measures. Fig. 11 showed that the HR of female assessors significantly decreased in the university study area as compared to the bus stop after eating ice cream. However, the HR of male assessors had no significant differences in the laboratory, café, university study area, and bus stop environments (See Fig. 12).

\section{Discussion}

\subsection{Dominance of ice cream flavour perception varied in the different eating environments}

Results from this study have demonstrated that ice cream flavour perception was affected by the consumption environment. In the laboratory, chocolate ice cream was initially dominated by sweetness and 


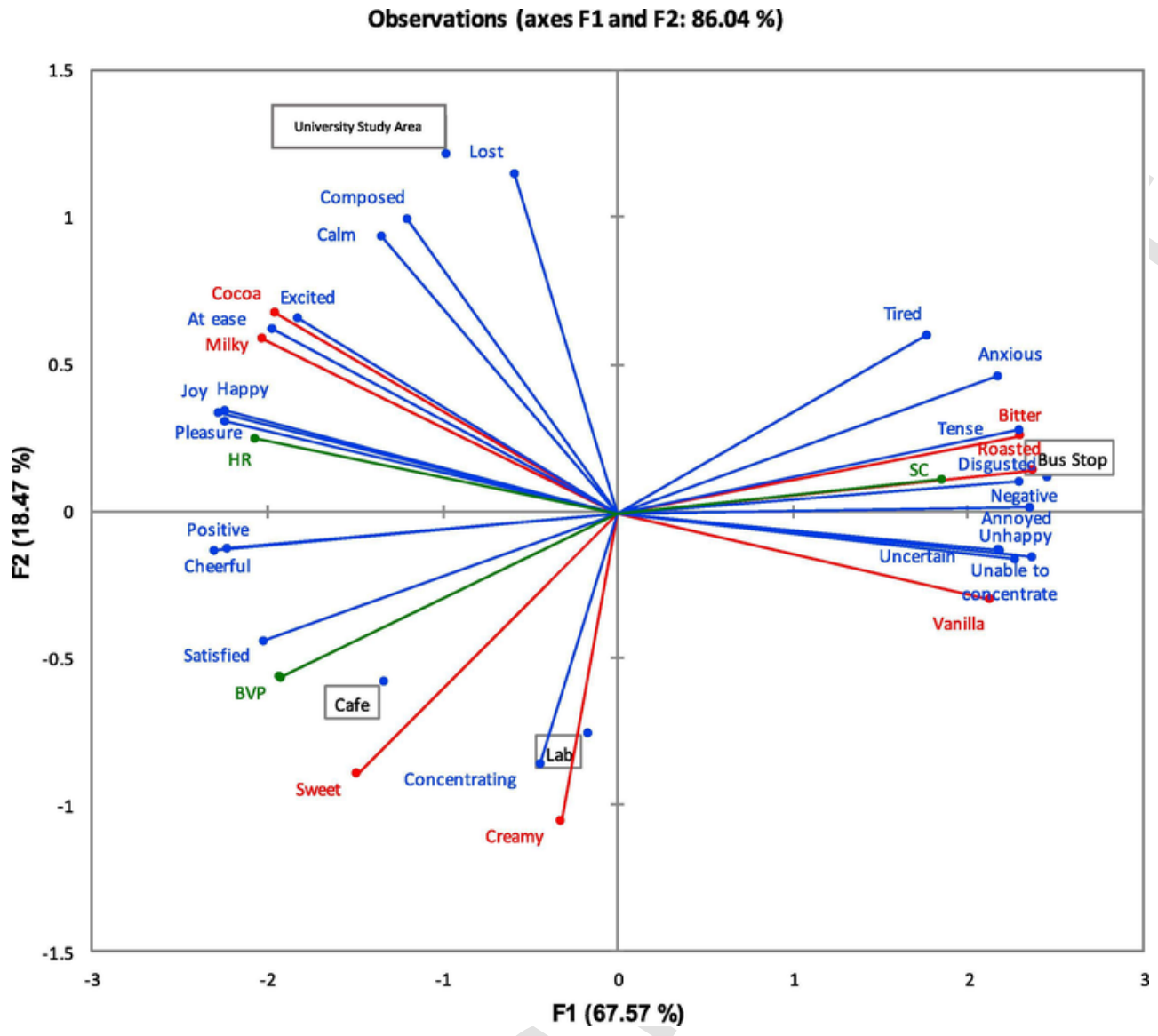

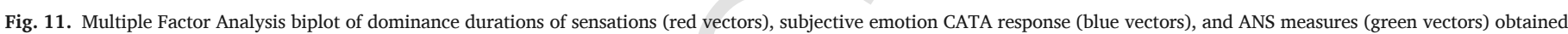

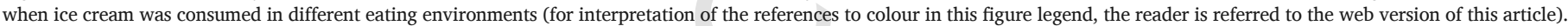

Environment*Gender

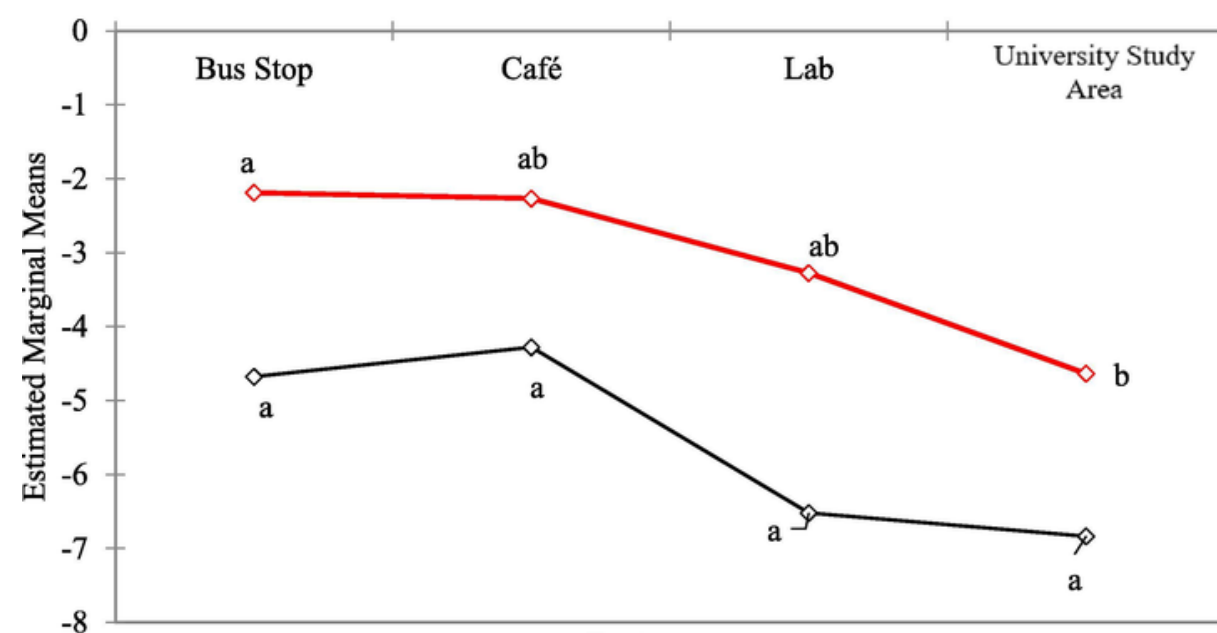

Environment

\section{$\prec$ Male $\leadsto$ Female}

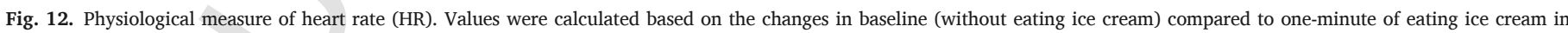
terms of gender and environment conditions. Different ${ }^{\mathrm{a}, \mathrm{b}, \mathrm{c}, \mathrm{d}}$ superscripts indicate significant differences in physiological values using the Tukey's multiple comparison tests.

creaminess at the start of consumption and then roasted and cocoa at the end. Kantono et al. (2018) recently reported that bittersweet chocolate gelato was initially perceived as sweet and creamy when eaten in a quiet laboratory environment.
Cocoa flavour was dominant in both the café and study space compared to laboratory and bus stop environments, but was at a higher dominance rate in the bus stop from early on until the end of consumption. The consumption of ice cream in the study space was associated 
with milky and cocoa flavour, a finding that is consistent with Pound et al. (2000). Petit and Sieffermann (2007) further reported that milkiness ratings of milk-based iced coffee were higher in a meeting room as compared to the laboratory. Zhang (2017) reported that ratings of sweetness and milkiness, of modified protein beverages were significantly higher at home compared to the central location chosen (location not specified).

At the bus stop, sweetness was dominant at the start of mastication but at a lower dominance level than the laboratory and café. This was followed by a prolonged dominance of bitterness that was then interrupted by creaminess. Similarly, the consumption of bittersweet chocolate gelato was associated with bitterness (Kantono, Hamid, Shepherd, Yoo, et al., 2016; Kantono et al., 2018), and significantly less pleasant when listening to disliked music (Kantono, Hamid, Shepherd, Yoo, Carr, et al., 2016). Interestingly, Kantono et al. (2018) also found that creaminess was dominant when first consuming bittersweet chocolate gelato while listening to disliked music. They postulated that this may have been attributable to the fact that disliked music acted as a mild stressor that may lead to creamy flavour being perceived. Torres and Nowson (2007) found that participants desired high-fat food, such as ice cream (Guinard et al., 1997), when stressed (see also Spence, 2017b), which might also explain why creamy was dominant in this study in the noisy and eventful bus stop environment. Interestingly, creaminess of ice cream in Lin, Hamid, Shepherd, Kantono, and Spence (2019) was shown to correlate with the valent park condition. This suggests that perhaps other mechanism instead of the aforementioned stress mechanism may have taken place while listening to soundscapes compared to music.

\subsection{Affective dimensions varied in different eating environments}

The affective states (i.e., valence, arousal, dominance) of this study based on the Mehrabian-Russell model (M-R model) were used to explain the participants' emotional responses to the four eating environments after consuming chocolate ice cream. In this study, valence ratings were significantly higher in the café and university study area environments after consuming chocolate ice cream as compared to the laboratory and bus stop. Interestingly, this study also revealed that the psychoacoustical characteristics of the cafe soundscape was considered the most pleasant in terms of having the highest fluctuation and low roughness, and the bus stop environment was the least pleasant in terms of having the least fluctuation and highest roughness. Özcan and van Egmond (2012) reported that participants listening to mechanical sounds with higher roughness found them significantly unpleasant compared to cyclic sounds with lower roughness. Ruotolo et al. (2013) further reported that participants were significantly annoyed when watching the audio-visual PIII motorway with higher loudness and roughness compared to the PII motorway condition with lower loudness and roughness. Similarly, Kantono, Hamid, Shepherd, Yoo, Carr, et al. (2016) demonstrated that valence ratings were significantly higher in a café after consuming the dark, bittersweet and milk chocolate gelato compared to a control silent environment.

In this study, the arousal ratings were significantly higher in the café and study space after consuming ice cream than the bus stop and laboratory. High arousal and valence ratings are related to appetitive (i.e., approach) behaviours, while high arousal and low valence ratings were related to defensive (i.e., avoidance) behaviours (Bradley \& Lang, 2000; Bradley, Codispoti, Cuthbert, \& Lang, 2001). Café and university study area environments evoked desirable sensory attributes (e.g. sweetness, cocoaness) in chocolate ice cream. The bus stop (i.e. low arousal, low valence, low dominance) on the other hand evoked non-desirable attributes.

The dominance rating was significantly increased in the study space and café environments after consuming ice cream compared to the bus stop. Kantono, Hamid, Shepherd, Lin, et al. (2016) also showed that dominance ratings are significantly increased in a café after consuming gelato compared to a control silent condition.

\subsection{Ice cream consumed in different environments evoked different emotions}

The cognitive theory of emotion argues that the subjective evaluation of emotion by participants can be affected by environment factors (Lazarus, 1991). In addition, Piqueras-Fiszman and Jaeger (2014a,b) have demonstrated that the suitability and context of an eating environment has a significant effect on a multitude of emotions. In this study, the emotional responses of participants varied across the four different environments after eating ice cream. In preliminary trials carried out to identify the emotions elicited by the different eating environments, the university study area had the highest number of positive emotions followed by the café. Many studies have shown that restaurant environments are typically related to positive emotions (Hyun \& Kang, 2014; Jang \& Ryu, 2007; Prayag et al., 2014). In the present study, positive emotions of pleasure, happy, positive and satisfied were rated significantly higher in the café and university study area compared to the laboratory and bus stop after consuming chocolate ice cream. Prayag et al. (2014) showed that the atmospherics of restaurants in the French Riviera had a significantly positive effect on the positive emotions of consumers in terms of their relaxation, pleasure, and excitement. Jang and Ryu (2007) further reported that the high-quality ambience of high-class restaurants had significant effects on the emotions of happiness, pleased, entertained, and delighted of participants. Similarly, Danner et al. (2016) reported that positive emotions of energetic, happy and loving were rated significantly higher in a restaurant after consuming wine compared to home and the laboratory environments. Dorado et al. (2016) further demonstrated that the positive emotion of excitement was significantly higher in a public bar when consuming beer while talking with friends compared to not having friends around.

The bus stop elicited a large number of negative emotions in preliminary trials carried out in this study to document the emotions elicited by this environment. This study further revealed that negative emotions of being unable to concentrate, uncertain about things, negative, tired, tense, unhappy, annoyed and anxious were rated significantly higher in the bus stop compared to the laboratory, university study area and café environments after consuming chocolate ice cream. Ulrich et al. (1991) reported that aggression was significantly increased in a traffic environment as compared to a pedestrian mall. Paunović et al. (2014) further reported that public transport noise during the day elicited higher levels of annoyance than people in areas without public transport noise.

Emotions evoked in the four different environments might be related to the varying affective dimensions of the different environments. The university study area and café environments were found in this study to be more pleasant and were linked to positive emotions. Negative emotions on the other hand were related to the least pleasant environment, that is, the bus stop. In addition, the laboratory was found to elicit a reduced range of emotions compared to the other three environments.

\subsection{Different eating environments correlated with different emotions}

Environmental factors can influence emotions. Barrett, Mesquita, Ochsner, and Gross (2007) demonstrated that emotions were not just influenced by the stimulus itself, but were also influenced by psychosocial factors. In this study, the laboratory was only correlated to the emotion of concentrating. On the other hand, the cafe and university study area environments were rated as the most pleasant, and were 
correlated to more positive emotions after consuming chocolate ice cream. The university study area environment was associated with the positive emotions of calm, excited, and at ease. The café was further correlated to positive emotions of joy, happy, pleasure, cheerful, positive and satisfied. Kim and Moon (2009) found that the ambience, aesthetics, layout, electric equipment, and seating comfort of theme restaurants in Alberta and Canada had significantly increased positive emotions. Jang and Ryu (2007) similarly reported that the aesthetics and ambience of high-class restaurants had significant effects on the following emotions: happy, pleased, entertained, and delighted.

On the other hand, the bus stop was found to be the least pleasant and was correlated to more negative emotions including tense, tired, negative, anxious, annoyed, unhappy, unable to concentrate, and uncertain about things. Urban and Máca (2013) found that listening to road and railway noises evoked the negative emotion of annoyance due to noise that had a negative effect on participants' satisfaction.

\subsection{Relationship between perception and emotional responses in different eating environments}

Emotional feelings can affect perception (Danner et al., 2016; Jaeger, Spinelli, Ares, \& Monteleone, 2018; Köster \& Mojet, 2015). In this study, only the positive emotion of concentrating was related to creamy flavour in the laboratory environment. This may because the laboratory constitutes a controlled environment (Kozlowska et al., 2003), and participants were much more likely to concentrate in this environment and consequently it did not evoke as many emotions as the other environments.

The present results further provide support for the role of emotional valence of stimuli in mediating crossmodal correspondences between eating environments and flavour perception. The negative emotions of tense, tired, anxious, negative, annoyed, unable to concentrate, unhappy and uncertain about things were associated with bitter and roasted flavours in the bus stop. Similarly, some studies have shown that negative emotions are associated with bitter taste. Kantono, Hamid, Shepherd, Yoo, et al. (2016) demonstrated that the negative emotions of disgust, contempt and disappointment were related to bitterness when consuming gelato while exposed to disliked music. Likewise, Jager et al. (2014) showed that the negative emotions of boredom and aggression were related to bitterness when consuming $70 \%$ cocoa chocolate.

In the current study, the positive emotions of happy, pleasure, joy, cheerful, positive and satisfied were associated with sweetness in the café. Studies have also reported that positive emotions are associated with sweet taste. Kantono, Hamid, Shepherd, Yoo, et al. (2016) correlated positive emotions of happiness, satisfaction to sweet taste when consuming chocolate gelato while listening to liked music. Likewise, Jager et al. (2014) demonstrated that positive emotions of interested, happy, and loving were related to the sweetness of orange and blueberry flavour chocolate. Thomson, Crocker, and Marketo (2010) also reported that positive emotions of fun and easy-going were related to the sweetness of chocolate.

Interestingly, it was also found that the positive emotions of relaxation and excitement were related to milkiness in the university study area environment. Similarly, Kantono et al. (2018) showed that positive emotions of amusement, enjoyment, love, happiness, and satisfaction were related to milkiness when consuming gelato while listening to music differing in pleasantness. In addition, positive emotions of calm, at ease and excited were associated with cocoa flavour in the university study area environment. No studies have reported the association between the positive emotions like calm, at ease and excited, and cocoa flavour. Only Thomson et al. (2010) reported that positive emotions of energetic and powerful were related to cocoa flavour when consuming dark chocolate in the laboratory.
Based on the data reported here, it was found that valence dimensions of the real eating environments affected both emotions and perceptions more than the controlled laboratory environment. Pleasant environments (café, university study area) resulted in positive emotions that are related to sweet, cocoa and milkiness. The least pleasant environment (bus stop) resulted in negative emotions related to bitter and roasted flavours.

\subsection{Consuming ice cream in different eating environments influenced electrophysiological responses}

After consuming chocolate ice cream, SC was significantly higher in the university study area, café, and bus stop as compared to the laboratory. In this study, the sharpness and roughness of bus stop and café environments were higher than the laboratory. The sensory pleasantness of participants decreased with the increase in sharpness, loudness and roughness of sounds as stated in the Zwicker's model of psychoacoustics and sensory pleasantness (Fastl \& Zwicker, 2007). Parsons, Tassinary, Ulrich, Hebl, and Grossman-Alexander (1998) reported that SC of participants significantly increased in an unpleasant urban roadside environment as compared to the forest roadside environment. Alvarsson et al. (2010) further reported that their participants' SC increased significantly in unpleasant high noise condition compared to the nature sound condition. The reason as to why SC was increased may be due to the increase of mental stress when listening to noise (Sun et al., 2010).

HR was significantly decreased in the university study area compared to the bus stop after consuming chocolate ice cream. Zhai and Barreto (2006) reported that HR increased when people were under stress. Studies have shown that HR can be significantly influenced by the environment. Laumann, Gärling, and Stormark (2003) reported that the HR of participants significantly decreased when watching videos on nature films compared to urban environments. Meanwhile, Labbé, Schmidt, Babin, and Pharr (2007) showed that the HR of participants significantly decreased under the self-selecting relaxing and classical music conditions, as compared to the heavy metal music conditions following a stressor.

\section{Conclusion}

This study set out to determine how emotions and electrophysiological measures influenced temporal changes in the perception of the flavour of chocolate ice cream consumed in different eating environments. The dominant flavour attributes of ice cream were found to vary in different environments, in particular, covarying with affective dimensions, emotions and electrophysiological measures. Consumption of ice cream in the different eating environments influenced temporal changes in flavour, the emotions evoked, and electrophysiological measures. Valence dimensions measured in real eating environments affected both emotions and perceptions more than in the laboratory environment. Eating ice cream in different eating environments also resulted in significant changes in SC and HR. The results of this research support the notion that emotion, measured both by self-report and electrophysiologically, influenced temporal changes in flavour perception of chocolate ice cream when consumed in the different environments. This research contributes additional evidence that suggests the importance of considering electrophysiological measurements of participants while eating to explain changes in perception of food. Further research can further explore how different eating contexts can influence the flavour perception, emotions and electrophysiological measures obtained when consuming more complex foods (e.g., fried chicken and pizza). The findings reported in the present study revealed that that eating environment can give rise to changes in the temporal dynamics of multisensory flavour perception in the case of ice cream. 
Such results may have important marketing implications for the marketing of food as multisensory experiences in real eating environments can be manipulated to provide stimulants that can improve the perception of the flavour of food without necessarily changing the flavour of food itself. The current study goes some way towards enhancing our understanding on how environments in which food is consumed affect perception. In addition, further studies can focus on the control for emotional state which should prior to entering eating context (e.g. going to a café to relax, or study space to study already stressed). This information can be used to develop targeted interventions aimed at improving perception of food in real-world eating environments.

\section{Uncited references}

\section{Acknowledgment}

The authors acknowledge the School of Science at AUT for PBRF funds to support this research.

\section{References}

Alvarsson, J.J., Wiens, S., Nilsson, M.E., 2010. Stress recovery during exposure to nature sound and environmental noise. International Journal of Environmental Research and Public Health 7 (3), 1036-1046.

Ares, G., Jaeger, S.R., Antúnez, L., Vidal, L., Giménez, A., Coste, B., ... Castura, J.C., 2015. Comparison of TCATA and TDS for dynamic sensory characterization of food products. Food Research International 78, 148-158.

Bangcuyo, R.G., Smith, K.J., Zumach, J.L., Pierce, A.M., Guttman, G.A., Simons, C.T., 2015. The use of immersive technologies to improve consumer testing: The role of ecological validity, context and engagement in evaluating coffee. Food Quality and Preference 41, 84-95.

Barrett, L.F., 2016. Navigating the science of emotion. In: Meiselman, H. (Ed.), Emotion measurement. Woodhead Publishing, USA, pp. 31-63.

Barrett, L.F., Mesquita, B., Ochsner, K.N., Gross, J.J., 2007. The experience of emotion. Annual Review of Psychology 58, 373-403.

Bell, R., Meiselman, H.L., Pierson, B.J., Reeve, W.G., 1994. Effects of adding an Italian theme to a restaurant on the perceived ethnicity, acceptability, and selection of foods. Appetite 22 (1), 11-24.

Belojevic, G., Jakovljevic, B., Stojanov, V., Paunovic, K., Ilic, J., 2008. Urban road-traffic noise and blood pressure and heart rate in preschool children. Environment International 34 (2), 226-231.

Bhumiratana, N., Adhikari, K., Chambers IV, E., 2014. The development of an emotion lexicon for the coffee drinking experience. Food Research International 61, 83-92.

Bradley, M.M., Codispoti, M., Cuthbert, B.N., Lang, P.J., 2001. Emotion and motivation I: Defensive and appetitive reactions in picture processing. Emotion 1 (3), 276-298.

Bradley, M.M., Lang, P.J., 1994. Measuring emotion: The self-assessment manikin and the semantic differential. Journal of Behavior Therapy and Experimental Psychiatry 25 (1), 49-59.

Bradley, M.M., Lang, P.J., 2000. Affective reactions to acoustic stimuli. Psychophysiology 37 (2), 204-215.

Daillant-Spinnler, B., Issanchou, S., 1995. Influence of label and location of testing on acceptability of cream cheese varying in fat content. Appetite 24 (2), 101-105.

Danner, L., Ristic, R., Johnson, T.E., Meiselman, H.L., Hoek, A.C., Jeffery, D.W., Bastian, S.E., 2016. Context and wine quality effects on consumers' mood, emotions, liking and willingness to pay for Australian Shiraz wines. Food Research International 89, 254-265.

Delarue, J., Sieffermann, J.M., 2004. Sensory mapping using Flash profile. Comparison with a conventional descriptive method for the evaluation of the flavour of fruit dairy products. Food Quality and Preference 15 (4), 383-392.

Desmet, P.M., Schifferstein, H.N., 2008. Sources of positive and negative emotions in food experience. Appetite 50 (2-3), 290-301.

Dishman, R.K., Nakamura, Y., Garcia, M.E., Thompson, R.W., Dunn, A.L., Blair, S.N., 2000. Heart rate variability, trait anxiety, and perceived stress among physically fit men and women. International Journal of Psychophysiology 37 (2), 121-133.

Dorado, R., Chaya, C., Tarrega, A., Hort, J., 2016. The impact of using a written scenario when measuring emotional response to beer. Food Quality and Preference 50, 38-47.

Dratva, J., Phuleria, H.C., Foraster, M., Gaspoz, J.M., Keidel, D., Künzli, N., ... Schindler, C., 2012. Transportation noise and blood pressure in a population-based sample of adults. Environmental Health Perspectives 120 (1), 50-55.

Dubowitz, T., Ghosh-Dastidar, M., Eibner, C., Slaughter, M.E., Fernandes, M., Whitsel, E.A., ... Michael, Y.L., 2012. The women's health initiative: The food environment, neighborhood socioeconomic status, BMI, and blood pressure. Obesity 20 (4), 862-871.

Edwards, J.S., Gustafsson, I.B., 2008. The five aspects meal model. Journal of Foodservice 19 (1), 4-12.

Fastl, H., Zwicker, E., 2007. Psychoacoustics: Facts and models. Springer Science \& Business Media.

Guinard, J.X., Zoumas-Morse, C., Mori, L., Uatoni, B., Panyam, D., Kilara, A., 1997. Sugar and fat effects on sensory properties of ice cream. Journal of Food Science 62 (5), 1087-1094.
Hersleth, M., Mevik, B.H., Næs, T., Guinard, J.X., 2003. Effect of contextual factors on liking for wine-Use of robust design methodology. Food Quality and Preference 14 (7), 615-622.

Hersleth, M., Ueland, , Allain, H., Næs, T., 2005. Consumer acceptance of cheese, influence of different testing conditions. Food Quality and Preference 16 (2), 103-110.

Heung, V.C., Gu, T., 2012. Influence of restaurant atmospherics on patron satisfaction and behavioral intentions. International Journal of Hospitality Management 31 (4), 1167-1177.

Holthuysen, N.T., Vrijhof, M.N., de Wijk, R.A., Kremer, S., 2017. "Welcome on board": Overall liking and just-about-right ratings of airplane meals in three different consumption contexts-Laboratory, re-created airplane, and actual airplane. Journal of Sensory Studies 32 (2), e12254.

Hu, X., Lee, J., 2018. Emotions elicited while drinking coffee: A cross-cultural comparison between Korean and Chinese consumers. Food Quality and Preference

Hyun, S.S., Kang, J., 2014. A better investment in luxury restaurants: Environmental or non-environmental cues?. International Journal of Hospitality Management 39, 57-70.

Jaeger, S.R., Spinelli, S., Ares, G., Monteleone, E., 2018. Linking product-elicited emotional associations and sensory perceptions through a circumplex model based on valence and arousal: Five consumer studies. Food Research International 109, 626-640.

Jager, G., Schlich, P., Tijssen, I., Yao, J., Visalli, M., De Graaf, C., Stieger, M., 2014. Temporal dominance of emotions: Measuring dynamics of food-related emotions during consumption. Food Quality and Preference 37, 87-99.

Jang, S., Liu, Y., Namkung, Y., 2011. Effects of authentic atmospherics in ethnic restaurants: Investigating Chinese restaurants. International Journal of Contemporary Hospitality Management 23 (5), 662-680.

Jang, S.S., Namkung, Y., 2009. Perceived quality, emotions, and behavioral intentions: Application of an extended Mehrabian-Russell model to restaurants. Journal of Business Research 62 (4), 451-460.

Jeong, E., Jang, S.S., 2011. Restaurant experiences triggering positive electronic word-of-mouth (eWOM) motivations. International Journal of Hospitality Management 30 (2), 356-366.

Jiang, W., Niimi, J., Ristic, R., Bastian, S.E.P., 2017. Effects of immersive context and wine flavor on consumer wine flavor perception and elicited emotions. American Journal of Enology and Viticulture 68 (1), 1-10.

Kantono, K., Hamid, N., Shepherd, D., Lin, Y.H.T., Brard, C., Grazioli, G., Carr, B.T., 2018 The effect of music on gelato perception in different eating contexts. Food Research International 113, 43-56.

Kantono, K., Hamid, N., Shepherd, D., Lin, Y.H.T., Skiredj, S., Carr, B.T., 2019. Emotional and electrophysiological measures correlate to flavour perception in the presence of music. Physiology \& Behavior 199, 154-164.

Kantono, K., Hamid, N., Shepherd, D., Lin, Y.H.T., Yakuncheva, S., Yoo, M.J., ... Carr, B.T., 2016. The influence of auditory and visual stimuli on the pleasantness of chocolate gelati. Food Quality and Preference 53, 9-18.

Kantono, K., Hamid, N., Shepherd, D., Yoo, M.J., Carr, B.T., Grazioli, G., 2016. The effect of background music on food pleasantness ratings. Psychology of Music 44 (5), 1111-1125.

Kantono, K., Hamid, N., Shepherd, D., Yoo, M.J., Grazioli, G., Carr, B.T., 2016. Listening to music can influence hedonic and sensory perceptions of gelati. Appetite 100, 244-255.

Kenny, D.A., 1987. Statistics for the social and behavioral sciences. Little, Brown, Boston, MA.

Kim, S.E., Lee, S.M., Kim, K.O., 2016. Consumer acceptability of coffee as affected by situational conditions and involvement. Food Quality and Preference 52, 124-132.

Kim, W.G., Moon, Y.J., 2009. Customers' cognitive, emotional, and actionable response to the servicescape: A test of the moderating effect of the restaurant type. International Journal of Hospitality Management 28 (1), 144-156.

King, S.C., Weber, A.J., Meiselman, H.L., Lv, N., 2004. The effect of meal situation, social interaction, physical environment and choice on food acceptability. Food Quality and Preference 15 (7-8), 645-653.

Kjellgren, A., Buhrkall, H., 2010. A comparison of the restorative effect of a natural en vironment with that of a simulated natural environment. Journal of Environmental Psychology 30 (4), 464-472.

Konttinen, H., Männistö, S., Sarlio-Lähteenkorva, S., Silventoinen, K., Haukkala, A., 2010 Emotional eating, depressive symptoms and self-reported food consumption. A population-based study. Appetite 54 (3), 473-479.

Köster, E.P., Mojet, J., 2015. From mood to food and from food to mood: A psychological perspective on the measurement of food-related emotions in consumer research. Food Research International 76, 180-191.

Kozlowska, K., Jeruszka, M., Matuszewska, I., Roszkowski, W., Barylko-Pikielna, N., Brzozowska, A., 2003. Hedonic tests in different locations as predictors of apple juice consumption at home in elderly and young subjects. Food Quality and Preference 14 (8), 653-661.

Kreibig, S.D., 2010. Autonomic nervous system activity in emotion: A review. Biological Psychology 84 (3), 394-421.

Kuo, T.B., Lin, T., Yang, C.C., Li, C.L., Chen, C.F., Chou, P., 1999. Effect of aging on gender differences in neural control of heart rate. American Journal of Physiology-Heart and Circulatory Physiology 277 (6), H2233-H2239.

Labbe, D., Schlich, P., Pineau, N., Gilbert, F., Martin, N., 2009. Temporal dominance of sensations and sensory profiling: A comparative study. Food Quality and Preference 20 (3), 216-221.

Labbé, E., Schmidt, N., Babin, J., Pharr, M., 2007. Coping with stress: The effectiveness of different types of music. Applied Psychophysiology and Biofeedback 32 (3-4), $163-168$.

Laumann, K., Gärling, T., Stormark, K.M., 2003. Selective attention and heart rate responses to natural and urban environments. Journal of Environmental Psychology 23 (2), 125-134.

Lazarus, R.S., 1991. Cognition and motivation in emotion. American Psychologist 46 (4), 352-367. 
Li, F., Harmer, P., Cardinal, B.J., Vongjaturapat, N., 2009. Built environment and changes in blood pressure in middle aged and older adults. Preventive Medicine 48 (3), 237-241.

Lin, Y.H.T., Hamid, N., Shepherd, D., Kantono, K., Spence, C., 2019. Environmental sounds influence the multisensory perception of chocolate gelati. Foods 8 (4), 124.

Lubin, B., Zuckerman, M., 1999. Manual for the MAACL-R: Multiple affect adjective check list-revised. EdITS/Educational and Industrial Testing Service.

Macht, M., Dettmer, D., 2006. Everyday mood and emotions after eating a chocolate bar or an apple. Appetite 46 (3), 332-336.

McNair, D.M., Lorr, M., Droppleman, L.F., 1971. Profiles of mood states. Educational and Industrial Testing Services, San Diego, CA.

Mehrabian, A., Russell, J.A., 1974. A verbal measure of information rate for studies in environmental psychology. Environment and Behavior 6 (2), 233-252.

Meiselman, H.L., 2017. Emotion measurement: Theoretically pure or practical?. Food Quality and Preference 62, 374-375.

Meiselman, H.L., Johnson, J.L., Reeve, W., Crouch, J.E., 2000. Demonstrations of the in fluence of the eating environment on food acceptance. Appetite 35 (3), 231-237.

Nijs, I.M., Franken, I.H., Muris, P., 2010. Food-related Stroop interference in obese and normal-weight individuals: Behavioral and electrophysiological indices. Eating Behaviors 11 (4), 258-265.

Özcan, E., van Egmond, R., 2012. Basic semantics of product sounds. International Journal of Design 6 (2), 41-54.

Parsons, R., Tassinary, L.G., Ulrich, R.S., Hebl, M.R., Grossman-Alexander, M., 1998. The view from the road: Implications for stress recovery and immunization. Journal of Environmental Psychology 18 (2), 113-140.

Paunović, K., Belojević, G., Jakovljević, B., 2014. Noise annoyance is related to the presence of urban public transport. Science of the Total Environment 481, 479-487.

Peltier, C., Visalli, M., Schlich, P., 2015. Canonical variate analysis of sensory profiling data. Journal of Sensory Studies 30 (4), 316-328.

Petit, C., Sieffermann, J.M., 2007. Testing consumer preferences for iced-coffee: Does the drinking environment have any influence?. Food Quality and Preference 18 (1), 161-172.

Pineau, N., de Bouillé, A.G., Lepage, M., Lenfant, F., Schlich, P., Martin, N., Rytz, A., 2012. Temporal Dominance of Sensations: What is a good attribute list?. Food Quality and Preference 26 (2), 159-165.

Pineau, N., Schlich, P., Cordelle, S., Mathonnière, C., Issanchou, S., Imbert, A., ... Köster, E., 2009. Temporal Dominance of Sensations: Construction of the TDS curves and comparison with time-intensity. Food Quality and Preference 20 (6), 450-455.

Piqueras-Fiszman, B., Jaeger, S.R., 2014. The impact of the means of context evocation on consumers' emotion associations towards eating occasions. Food Quality and Preference $37,61-70$.

Piqueras-Fiszman, B., Jaeger, S.R., 2014. Emotion responses under evoked consumption contexts: A focus on the consumers' frequency of product consumption and the stability of responses. Food Quality and Preference 35, 24-31.

Pound, C., Duizer, L., McDowell, K., 2000. Improved consumer product development. Part one: Is a laboratory necessary to assess consumer opinion?. British Food Journal 102 (11), 810-820.

Prayag, G., Khoo-Lattimore, C., Sitruk, J., 2014. Casual dining on the French Riviera: Examining the relationship between visitors' perceived quality, positive emotions, and behavioral intentions. Journal of Hospitality Marketing \& Management 24 (1), 24-46.

Rodrigues, J.F., Condino, J.P.F., Pinheiro, A.C.M., Nunes, C.A., 2016. Temporal Dominance of Sensations of chocolate bars with different cocoa contents: Multivariate approaches to assess TDS profiles. Food Quality and Preference 47, 91-96.

Rodrigues, J.F., de Souza, V.R., Lima, R.R., Carneiro, J.D.D.S., Nunes, C.A., Pinheiro, A.C.M., 2016. Temporal dominance of sensations (TDS) panel behavior: A preliminary study with chocolate. Food Quality and Preference 54, 51-57.

Ruotolo, F., Maffei, L., Di Gabriele, M., Iachini, T., Masullo, M., Ruggiero, G., Senese, V.P., 2013. Immersive virtual reality and environmental noise assessment: An innovative audio-visual approach. Environmental Impact Assessment Review 41, 10-20.

Russell, J.A., 2003. Core affect and the psychological construction of emotion. Psychological Review 110 (1), 145-172.

Ryu, K., Jang, S.S., 2007. The effect of environmental perceptions on behavioral intentions through emotions: The case of upscale restaurants. Journal of Hospitality \& Tourism Research 31 (1), 56-72.

Saint-Eve, A., Panouille, M., Capitaine, C., Deleris, I., Souchon, I., 2015. Dynamic aspects of texture perception during cheese consumption and relationship with bolus properties. Food Hydrocolloids 46, 144-152.

Scherer, K.R., 2005. What are emotions? And how can they be measured?. Social Science Information 44 (4), 695-729.

Schouteten, J.J., De Steur, H., Sas, B., De Bourdeaudhuij, I., Gellynck, X., 2017. The effect of the research setting on the emotional and sensory profiling under blind, ex- pected, and informed conditions: A study on premium and private label yogurt products. Journal of Dairy Science 100 (1), 169-186.

Seo, H.S., Hummel, T., 2010. Auditory-olfactory integration: congruent or pleasant sounds amplify odor pleasantness. Chemical Senses 36 (3), 301-309.

Soleymani, M., Chanel, G., Kierkels, J.J., Pun, T., 2008. Affective characterization of movie scenes based on multimedia content analysis and user's physiological emotional responses. December. In: Multimedia, 2008. ISM 2008. Tenth IEEE International Symposium on. IEEE, pp. 228-235.

Sosa, M., Martinez, C., Marquez, F., Hough, G., 2008. Location and scale influence on sensory acceptability measurements among low-income consumers. Journal of Sensory Studies 23 (5), 707-719.

Spence, C., 2017. Gastrophysics: The new science of eating, Viking Penguin, London, UK.

Spence, C., 2017. Comfort food: A review. International Journal of Gastronomy and Food Science 9, 105-109.

Spence, C., 2019. Do men and women really live in different taste worlds?. Food Quality and Preference 73, 38-45.

Spinelli, S., Monteleone, E., 2018. Emotional response to products. In: Ares, G., Varela, P. (Eds.), Methods in consumer research. Woodhead Publishing, Cambridge, UK, pp. 261-296.

Stafford, L.D., Fernandes, M., Agobiani, E., 2012. Effects of noise and distraction on alcohol perception. Food Quality and Preference 24 (1), 218-224.

Stroebele, N., De Castro, J.M., 2004. Effect of ambience on food intake and food choice. Nutrition 20 (9), 821-838.

Sun, F.T., Kuo, C., Cheng, H.T., Buthpitiya, S., Collins, P., Griss, M., 2010. Activity-aware mental stress detection using physiological sensors. October. In: International Conference on mobile computing, applications, and services. Springer, Berlin, pp. 282-301.

Thayer, J.F., Åhs, F., Fredrikson, M., Sollers III, J.J., Wager, T.D., 2012. A meta-analysis of heart rate variability and neuroimaging studies: Implications for heart rate variability as a marker of stress and health. Neuroscience \& Biobehavioral Reviews 36 (2), 747-756.

Thompson, W.F., Schellenberg, E.G., Letnic, A.K., 2012. Fast and loud background music disrupts reading comprehension. Psychology of Music 40 (6), 700-708.

Thomson, D.M., Crocker, C., Marketo, C.G., 2010. Linking sensory characteristics to emotions: An example using dark chocolate. Food Quality and Preference 21 (8), 1117-1125.

Torres, S.J., Nowson, C.A., 2007. Relationship between stress, eating behavior, and obesity. Nutrition 23 (11-12), 887-894.

Ulrich, R.S., Simons, R.F., Losito, B.D., Fiorito, E., Miles, M.A., Zelson, M., 1991. Stress recovery during exposure to natural and urban environments. Journal of Environmental Psychology 11 (3), 201-230.

Urban, J., Máca, V., 2013. Linking traffic noise, noise annoyance and life satisfaction: A case study. International Journal of Environmental Research and Public Health 10 (5), 1895-1915.

Wang, J., Mesz, B., Riera, P., Spence, C. (2018). Analysing the impact of music on wine perception via temporal dominance of sensations. In: Oral presentation given at ICMPC15/ESCOM10. Graz, Austria: 23rd-28th July.

Wang, Q., Spence, C., 2018. "A sweet smile": the modulatory role of emotion in how extrinsic factors influence taste evaluation. Cognition and Emotion 32 (5), 1052-1061.

Warriner, A.B., Kuperman, V., Brysbaert, M., 2013. Norms of valence, arousal, and dominance for 13,915 English lemmas. Behavior Research Methods 45 (4), 1191-1207.

Watson, D., Clark, L.A., Tellegen, A., 1988. Development and validation of brief measures of positive and negative affect: The PANAS scales. Journal of Personality and Social Psychology 54 (6), 1063-1070.

Wioleta, S., 2013. Using physiological signals for emotion recognition. June. In: Human System Interaction (HSI), 2013 The 6th International Conference on. IEEE, pp. 556-561.

Woods, A.T., Poliakoff, E., Lloyd, D.M., Kuenzel, J., Hodson, R., Gonda, H., Thomas, A., 2011. Effect of background noise on food perception. Food Quality and Preference 22 (1), 42-47.

Zhai, J., Barreto, A., 2006. Stress detection in computer users based on digital signal processing of noninvasive physiological variables. August. In: Engineering in Medicine and Biology Society, 2006. EMBS'06. 28th Annual International Conference of the IEEE. IEEE, pp. 1355-1358.

Zhang, M., 2017. Comparison of the role of a central location test versus a home usage test on consumer perception of ready-to-mix protein beverages. MSc thesis North Carolina State University, North Carolina, USA.

Zhang, L., \& Han, K. (2009). How to analyze change from baseline: Absolute or per centage change? Available from: http://www.statistics.du.se/essays/D09 Zhang\%20Ling\%20\&\%20Han\%20Kun.pdf. 